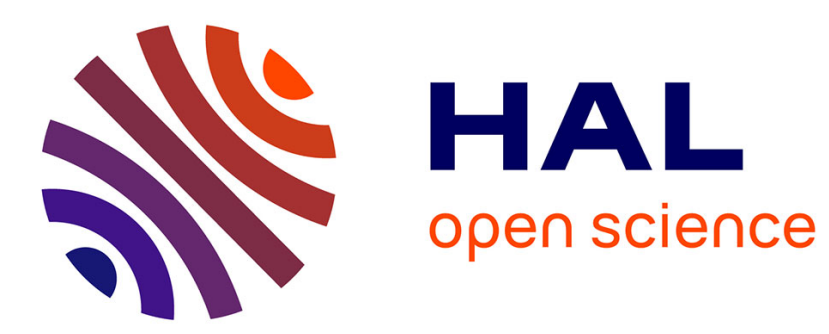

\title{
A Longitudinal Person-Centered Perspective on Positive and Negative Affect at Work
}

\author{
Emilie Sandrin, Alexandre J.S. Morin, Claude Fernet, Nicolas Gillet
}

\section{To cite this version:}

Emilie Sandrin, Alexandre J.S. Morin, Claude Fernet, Nicolas Gillet. A Longitudinal Person-Centered Perspective on Positive and Negative Affect at Work. Journal of Psychology, 2020, 154 (7), pp.499-532. 10.1080/00223980.2020.1781033 . hal-03142259

\section{HAL Id: hal-03142259 \\ https://hal.science/hal-03142259}

Submitted on 15 Feb 2021

HAL is a multi-disciplinary open access archive for the deposit and dissemination of scientific research documents, whether they are published or not. The documents may come from teaching and research institutions in France or abroad, or from public or private research centers.
L'archive ouverte pluridisciplinaire HAL, est destinée au dépôt et à la diffusion de documents scientifiques de niveau recherche, publiés ou non, émanant des établissements d'enseignement et de recherche français ou étrangers, des laboratoires publics ou privés. 
Running Head: POSITIVE AND NEGATIVE AFFECT

A Longitudinal Person-Centered Perspective on Work-Related Positive and Negative Affect

Emilie Sandrin ${ }^{1}$, Alexandre J. S. Morin ${ }^{2} *$, Claude Fernet ${ }^{3}$, and Nicolas Gillet ${ }^{1}$

${ }^{1}$ Université de Tours, France

${ }^{2}$ Concordia University, Canada

${ }^{3}$ Université du Québec à Trois-Rivières, Canada

The second author was supported by a grant from the Social Science and Humanity Research Council of Canada (435-2018-0368) in the preparation of this manuscript.

* The first two authors (E.S. \& A.J.S.M) contributed equally to this article and their order was determined at random: Both should thus be considered first authors.

\author{
Corresponding author: \\ Nicolas Gillet, \\ Université de Tours, \\ Faculté Arts et Sciences Humaines, \\ Département de psychologie, \\ 3 rue des Tanneurs, 37041 Tours Cedex 1, France \\ E-mail: nicolas.gillet@univ-tours.fr
}

This is the prepublication version of the following manuscript:

Sandrin, E., Morin, A. J. S., Fernet, C., \& Gillet, N. (in press). A longitudinal person-centered perspective on positive and negative affect at work. Journal of Psychology: Interdisciplinary and Applied. DOI: 10.1080/00223980.2020.1781033.

(C) 2020. This paper is not the copy of record and may not exactly replicate the authoritative document published in the Journal of Psychology: Interdisciplinary and Applied.

\begin{abstract}
This research examines how the direction and intensity of employee's positive and negative affect at work combine within different profiles, and the relations between these profiles and theoreticallyrelevant predictors (psychological need satisfaction and supervisor autonomy support) and outcomes (work-family conflict, absenteeism, and turnover intentions). A total sample of 491 firefighters completed our measures initially, and 139 of those completed the same measures again four months later, allowing us to examine the stability of these affect profiles over time. Latent profile analyses and latent transition analyses revealed five identical profiles across the two measurements occasions: 1Low Negative Affect Facilitators; 2- Moderately Low Positive Affect Incapacitators; 3- High Positive Affect Facilitators; 4- Very Low Positive Affect Incapacitators; and 5- Normative. Membership into Profiles 3, 4, and 5 was very stable over time. In contrast, Profiles 1 and 2 were associated with a highly unstable membership over time. The highest levels of work-family conflict, absenteeism, and turnover intentions were associated with the Very Low Positive Affect Incapacitators. In contrast, the lowest levels of turnover intentions were associated with the Low Negative Affect Facilitators and High Positive Affect Facilitators.
\end{abstract}

Keywords: Positive and negative affect, intensity and direction, latent transition analysis, profiles, selfdetermination theory. 
Employees can experience work affect (i.e., a broad range of feelings that people experience at work, encompassing both emotions and moods; George, 1996) likely to facilitate or impair their job performance (Daniels, Glover, \& Mellor, 2014; Scheibe, Yeung, \& Doerwald, 2018). Recent research has also focused on the direction component of affect, hereafter defined as workers' perceptions of affect as playing a role ranging from impairing their job performance (low levels of direction) to facilitating it (high levels of direction) (Martinent \& Nicolas, 2016, 2017b). Indeed, although positive affect has a positive valence and negative affect has a negative valence, both can be perceived by workers as contributing to facilitate or to impair their job performance (Nicolas, Martinent, \& Campo, 2014). When considered in isolation, positive and negative affect intensity and direction could both be considered as key drivers of a variety of outcomes relevant for both the employees themselves, and for their workplaces (Martinent \& Nicolas, 2017b; Nicolas et al., 2014). For instance, the benefits of experiencing high levels of positive affect (Fredrickson, 2014), especially in the work context, are well documented. Indeed, prior research has shown that employees' positive affect intensity was associated with higher levels of job satisfaction, and lower levels of burnout and turnover intentions (McNall, Tombari, \& Brown, 2019; Zhao, Li, \& Shields, 2019). Conversely, employees' negative affect intensity was associated with higher levels of burnout and productivity loss, and lower levels of engagement at work (Ferreira, da Costa Ferreira, Cooper, \& Oliveira, 2019; Zhao et al., 2019). However, despite their interest, these previous investigations are limited as they did not examine the possible combined effects of these four components of work affect (i.e., positive and negative affect intensity and direction) among samples of employees.

In contrast, person-centered analyses seek to identify subpopulations, referred to as profiles, of employees characterized by distinct configurations on a set of interacting variables (Marsh, Lüdtke, Trautwein, \& Morin, 2009; Morin \& Wang, 2016), making them naturally suited to investigating the combined effects of employees' positive and negative affect intensity and direction (Martinent \& Nicolas, 2017a). Recently, person-centered studies began to look at how positive and negative affect intensity and direction combine with one another within specific profiles of athletes (Martinent \& Nicolas, 2017a; Martinent, Nicolas, Gaudreau, \& Campo, 2013). Unfortunately, these prior investigations were limited to athletes, making it hard to generalize to working populations. Additional research is thus needed to identify the various profiles characterizing positive and negative affect intensity and direction in the workplace, their stability over time, and their associations with predictors (e.g., supervisor autonomy support, autonomy, relatedness, and competence needs satisfaction) and outcomes (e.g., turnover intentions, work-family conflict, absenteeism). This issue is important for theoretical purposes as profiles should provide a more realistic and holistic view of work affect via a more nuanced consideration that ventures beyond the specific or relative impact of single components. Moreover, given that person-centered results tend to be more naturally aligned with managers tendency to think about their employees as corresponding to different categories (Morin, Morizot, Boudrias, \& Madore, 2011; Zyphur, 2009), our findings are likely to have important implications for practice. Thus, rather than having to decode complex patterns of interrelations and interactions between variables, person-centered results allows managers to easily identify types of employees with knowledge about the likely outcomes of corresponding to these various profiles, as well as actionable levers of intervention to increase the likelihood of more desirable affect profiles.

We address these gaps in the present study by adopting a person-centered approach allowing us to identify different profiles of positive and negative affect intensity and direction at work among a sample of firefighters. This focus on firefighters is itself important given the importance of this understudied profession for handling a variety of critical emergency or hazardous situations and thus ensuring societal security and stability. Unfortunately, a limited number of studies on affect has been conducted among samples of firefighters. This is worrisome given that these workers are known to represent a high strain occupational group (Beaton, Murphy, \& Pike, 1996). More precisely, firefighters are frequently expose to a variety of stressors, including exposure to various pathogens, hazardous materials, and heavy workloads, which are all likely to generate negative affect intensity (Sandrin, Gillet, Fernet, Leloup, \& Depin- Rouault, 2019). Nevertheless and fortunately, they can also benefit from resources such as supervisor recognition that may help them to experience positive affect intensity (Sandrin, Gillet, Fernet, Depin- Rouault et al., 2019).

\section{Positive and Negative Affect}

Positive and negative valence may be used to group work affect in broad dimensions. Positive 
affect refers to pleasant engagement, energy, and concentration. In contrast, negative affect refers to an unpleasant engagement and a feeling of distress (Watson, Clark, \& Tellegen, 1988). Contrary to negative affect, positive affect has been shown to facilitate job performance by affecting the employees' behavioral, motivational, physical, and/or cognitive functioning (Fredrickson, 2014; Mäder \& Niessen, 2017). However, recent studies examining the underlying functionality (i.e., direction) that individuals attach to their positive and negative affect in sport (e.g., Nicolas et al., 2014) revealed that high levels of positive and negative affect could both be perceived either as facilitating or impeding sport performance, and provided strong support for the need to jointly consider positive and negative affect intensity and direction in future research.

More specifically, Nicolas et al. (2014) demonstrated that the intensity of positive affect was strongly and positively linked to positive affect direction (where high levels of direction suggest a facilitating role), whereas negative affect intensity was weakly and negatively related to negative affect direction before competition. When considering affect intensity, their findings revealed that positive and negative affect intensity before or during competition was related to a higher level of task-oriented coping before and during competition, as well as to a higher level of distraction-oriented coping before competition. However, only the intensity of negative affect was related to a higher level of distraction-oriented coping during competition. Likewise, whereas the intensity of negative affect before and during competition was positively related to disengagement-oriented coping before and during competition, the intensity of positive affect shared negative or null relations with this type of coping. In contrast, only positive affect intensity, both before and during competition, shared associations with the attainment of sport achievement goals. When considering affect direction, results revealed positive associations between positive and negative affect direction before and during competition and the reliance on higher levels of task-oriented coping. Pre-competition levels of positive affect intensity were also positively related to distraction-oriented coping before competition and to achievement goal attainment, while negative affect intensity before competition was negatively related to distraction-oriented coping during competition. Finally, positive affect direction during competition was associated with lower levels of disengagement-oriented coping during competition. In a second study, these authors further demonstrated that, when controlling for its intensity, positive affect direction remained associated with lower levels of disengagement- and distraction-oriented coping. Likewise, when controlling for its intensity, negative affect direction was negatively related to distraction-oriented coping and positively related to achievement goal attainment.

When considering these findings, it is noteworthy that direction should not be singled out as a distinct theoretical element. Indeed, direction plays an integral role in the general appraisal process in which workers engage when dealing with external demands. Thus, once the initial work affect is experienced by an employee in terms of valence and intensity, this initial experience is assumed to automatically lead to a further appraisal process related to the anticipated effect of this affect on job performance (Martinent et al., 2013). More precisely, depending on the availability of the resources required to successfully manage the contextual demand or contingency that has generated this affect in the first place, employees could come to consider both positive and negative affect at work as having the potential to either support, or to impede, job performance. Generally, research evidence lends credence to the idea that employees can come to consider both positive and negative affect as having either positive or negative effects on their job performance (Martinent \& Nicolas, 2017b).

For these reasons, scholars encourage further research to simultaneously consider the intensity and direction of positive and negative affect in a way that makes it possible to assess their likely mutually reinforcing or compensatory effects (Martinent \& Nicolas, 2017a; Martinent et al., 2013). However, despite the theoretically inseparable nature of affect intensity and direction, very few studies have simultaneously considered both of these components of negative and positive affect (e.g., Nicolas et al., 2014), and none of these few investigations have been conducted among samples of workers. Indeed, previous studies conducted in the work area have often been limited in their consideration of the isolated effects of negative and positive affect intensity (e.g., Daniels et al., 2014; Mäder \& Niessen, 2017), leaving unknown the nature of the most commonly occurring work affect intensity/direction configurations, and their possible combined relations with significant predictors and outcomes.

A Person-Centered Approach to Positive and Negative Affect at Work

Despite the interest of the studies presented thus far, they remain limited in providing only a 
partial view of the reality. Indeed, these variable-centered investigations (e.g., correlations, regressions) focus on the identification of average relations occurring among a set of variables in the sample under study. Such analyses are unable to assess the possibility that subpopulations might exist among which these relations could differ, and remain a suboptimal way to study the combined interactive effects of four distinct constructs (i.e., the intensity and direction of positive and negative affect). A more direct way of looking at the combined effects of these affect components is provided by person-centered analyses. Person-centered analyses (e.g., latent profile analyses; LPA) explicitly relax the assumption of population homogeneity, being specifically designed to identify employees' profiles characterized by different configurations of work affect (Meyer \& Morin, 2016; Morin, 2016). The present study adopts such a person-centered approach with the main objective of examining how the intensity and direction of positive and negative affect jointly operate and combine among different profiles of employees. Indeed, the identification of affect profiles characterized by different levels of negative and positive affect intensity and direction should offer a robust heuristic to study work affect configurations, and to unpack their complex relationships with key outcomes and predictors. For instance, a person-centered approach might identify a profile characterized by high levels of positive affect intensity and direction, and low levels of negative affect intensity and direction, whereas another one could be characterized by high levels of positive affect intensity and direction coupled with equally high levels of negative affect intensity and direction. This approach is directly aligned with results from prior studies showing that workers rarely experience a single affect, but rather a complex configuration of work affect (e.g., Reio Jr. \& Ghosh, 2009).

From a theoretical perspective, positive and negative affect is rooted within a larger motivational system of approach and avoidance tendencies that are intricately related to employees' work attitudes and behaviors (Gable, Poole, \& Harmon-Jones, 2015). The activation of an approach motivational tendency, occurring via positive affect, has generally been linked to positive consequences, whereas the activation of an avoidance motivational tendency, occurring via negative affect, tends to be related to less adaptive outcomes (e.g., turnover intentions, absenteeism; Pekrun, Elliot, \& Maier, 2009; Porfeli, Lee, \& Weigold, 2012). The repeated co-occurrence of positive affect with positive outcomes and of negative affect with negative outcomes are likely to set the tone for the creation of a particular combination of affect intensity and direction (i.e., positive affect with a facilitative effect and negative affect with a detrimental effect; Martinent et al., 2013). As a result, positive affect can be both intensified and reinterpreted as favorable for job performance, whereas negative affect can be both attenuated and reinterpreted as hindering job performance. However, repeated experiences of successful affect regulation, leading to a lower intensity of affect reactions, also have the potential to create among employees a sense of low affect activation perceived as detrimental to job performance. In addition, some employees possess a strong preference for higher levels of negative affect intensity because of their capacity to use negative affect to energize, vitalize, and motivate their action (Martinent et al., 2013). Appraisals of job demands and contingencies as challenges rather than threats could explain the ability of some employees to translate negative affect into resources able to facilitate job performance and to simultaneously generate positive affect. In several other cases, however, negative affect intensity is likely to be associated with the perception that negative affect is detrimental to workers' performance (Cash \& Gardner, 2011; Gardner \& Fletcher, 2009).

Although no person-centered research on employees' affect profiles has so far been conducted in the work domain, indirect evidence coming from studies conducted on related-constructs, as well as in other contexts, may inform this question. A first source of information comes from person-centered research of affect conducted in the sport area, which has supported the idea that positive and negative affect intensity and direction coexist under different configurations among athletes (Martinent et al., 2013). More specifically, Martinent et al. (2013) identified athletes' profiles both before and during competition on the basis of their ratings of the intensity and direction of positive and negative affect. Four very similar profiles were identified both before and during competition: (1) high positive affect facilitators (high positive affect intensity with a facilitative effect on performance, and low negative affect intensity with a detrimental effect on performance); (2) facilitators (moderate to high positive affect intensity with a facilitative effect on performance, and average negative affect intensity with a 
facilitative effect on performance); (3) low affect incapacitators ${ }^{1}$ (low positive affect intensity with a detrimental effect on performance, and relatively low negative affect intensity with a neutral to detrimental effect on performance); and (4) high negative affect incapacitators (average positive affect intensity with a neutral effect on performance, and high negative affect intensity with a detrimental effect on performance). In a similar study, Martinent and Nicolas (2017a) identified three affect profiles similar to the second, third, and fourth profiles identified in their previous study among a sample of competitive athletes assessed before competition. Despite their consistency among independent samples of athletes, it remains hard to assess whether these findings will generalize to samples of working employees. Moreover, person-centered evidence is known to emerge from the accumulation of research conducted across a variety of contexts allowing one to better differentiate the core profiles that emerge systematically from those who only reflect sample-specific idiosyncrasies or context-specific characteristics (Morin, Meyer, Creusier, \& Biétry, 2016). The present study thus seeks to document work affect profiles defined based on positive and negative affect intensity and direction in a sample of employees, to identify qualitatively distinct subpopulations of employees characterized by distinct configurations of work affect (Meyer \& Morin, 2016).

A second source of information comes from person-centered research on employees' ratings of psychological health at work (encompassing ratings of distress and well-being). In this area of research, Mäkikangas et al. (2016) identified two profiles of job-related well-being: (1) a "High jobrelated affective well-being" profile characterized by high levels of positive and low levels of negative job-related affective states; and (2) a "Low job-related affective well-being" profile characterized by high levels of anxiety and depression, and low levels of comfort and enthusiasm. These authors also conducted a few additional studies adopting a longitudinal perspective of affective states profiles. Thus, in a diary study of five consecutive workdays, Mäkikangas et al. (2014) differentiated three profiles: (1) high stable vigor and low stable exhaustion, (2) high stable vigor and low decreasing exhaustion, and (3) high stable exhaustion and low stable vigor). Similarly, Mäkikangas, Hyvönen, and Feldt (2017) identified three distinct profiles showing: (1) low stable exhaustion and high stable vigor, (2) fluctuating low levels of exhaustion and fluctuating moderate levels of vigor, and (3) stable moderate exhaustion and high decreasing vigor. Finally, in a three-wave 10-year study, Mäkikangas, Hyvönen, Leskinen, Kinnunen, and Feldt (2011) also identified three profiles of job-related affective well-being: (1) high increasing positive affective states, and low and decreasing negative affective states, (2) moderate increasing depression, and moderate decreasing enthusiasm, and (3) low increasing positive affective states, and high decreasing negative affective states.

Perhaps more directly relevant to the present study, Morin, Boudrias, Marsh, Madore, and Desrumaux (2016) identified five distinct workers' profiles: (1) an adapted profile presenting moderately high levels of global psychological health, and relatively low levels of well-being (harmony, serenity, and involvement) and psychological distress (irritability, anxiety/depression, and distance); (2) a stressfully-involved profile presenting moderately low levels of global psychological health, high levels of involvement, irritability, and anxiety/depression, and average levels of harmony, serenity, and distance; (3) a normative profile presenting average levels of global psychological health and average levels on all other specific indicators; (4) an harmoniously-distanced profile presenting relatively low levels of global psychological health, moderately high levels of distance, harmony, and serenity, and moderately low levels of irritability, anxiety/depression, and involvement; and (5) a flourishing profile presenting very high levels of psychological health, average levels on all distress indicators, and high levels of on all well-being indicators. When we interpret these profiles in light of the affective combination mechanisms reported by Martinent et al. (2013), it is noteworthy that members of Profile 1 can be seen as low affect incapacitators, members of the Profile 2 as facilitators, members of Profile 4 as positive affect incapacitators, and members of Profile 5 as positive affect facilitators. In contrast, members of Profile 3 (normative) seem to correspond to employees who generally succeed in maintaining some form of emotional balance at work.

In sum, despite the fact that no research has ever looked at affect profiles in the work area, indirect

\footnotetext{
${ }^{1}$ Martinent et al. (2013) use the label "debilitators" to refer to members of profiles in which affect is seen has having a detrimental effect on performance. We feel that the label "incapacitators" is more linguistically accurate. The verb incapacitate implies some form of interference with one's capacity to function effectively, whereas the verb debilitate involves a more direct weakening of that person's capacity.
} 
evidence coming from person-centered research conducted in the sport setting (Martinent \& Nicolas, 2017a; Martinent et al., 2013) or looking at psychological health at work (Mäkikangas et al., 2011, 2014, 2016, 2017; Morin, Boudrias et al., 2016), allow us to propose the following hypotheses:

Hypothesis 1. When considering employees' configurations of negative and positive affect intensity and direction, we expect to identify three to five profiles.

Hypothesis 2. We expect to identify the following profiles: (1) High positive affect facilitators (high positive affect intensity with a facilitative effect on job performance, and moderate to low negative affect intensity with neutral to detrimental effects on job performance); (2) Low affect incapacitators (low to moderate levels of positive and negative affect intensity with a detrimental effect on job performance); (3) Facilitators (moderate to high levels of negative and positive affect intensity with a facilitative effect on job performance); and (4) Incapacitators (average to low positive affect intensity with a neutral effect on job performance, and high negative affect intensity with a detrimental effect on job performance).

Over and above the profiles mentioned in Hypothesis 2, we leave as an open research question whether the more unique profiles identified by Morin, Boudrias et al. (2016) would also be identified in the current research: (1) Normative (average levels of negative and positive affect intensity with neutral effects on performance); and (2) High positive affect incapacitators (high positive affect intensity with a detrimental effect on performance, and average to low negative affect intensity with a neutral effect on performance).

\section{A Longitudinal Person-Centered Perspective}

A second aim of the present research is to assess whether the profiles would remain stable over a period of four months. As noted by Meyer and Morin (2016; also see Meyer, Morin, \& Wasti, 2018), to support the use of person-centered results as guides for the development of intervention strategies tailored at distinct types, or profiles, of employees, it is critical to ascertain the stability of these results over time. Two distinct forms of longitudinal stability can, and should, be considered (Gillet, Morin, \& Reeve, 2017; Kam, Morin, Meyer, \& Topolnytsky, 2016). A first form of longitudinal stability, within-sample stability, is related to the nature of the profiles themselves, which could change over time. For example, the number or structure of the profiles could change over time, which would suggest that the profiles have only limited usefulness as intervention guides as they only reflect transient phenomenon, or that the sample under consideration has recently been exposed to some rather important internal or external changes. Morin, Meyer et al. (2016) refer to these two subtypes of within-sample profile stability as configural (same number of profiles) and structural (profiles with the same nature) similarity. In contrast, the passage of time or changing circumstances may alternatively lead to a change in the degree of similarity among members of specific profiles (dispersion similarity), or in the relative size of the profiles (distributional similarity). These two subtypes of within-sample profile stability do not preclude the reliance on person-centered solutions as guides for intervention, but suggest that the profiles show some degree of reactivity to internal or external changes, and may thus be impacted by proper interventions.

A second form of longitudinal stability, within-person stability, is related to changes in the degree to which employees correspond to specific profiles over time (Gillet, Morin, \& Reeve, 2017; Kam et al., 2016) and can be observed even in the absence of within-sample changes. For instance, observing a variable-centered increase in average levels of positive affect intensity could alternatively be translated, at the profile level, into: (a) a tendency for workers to transition toward profiles with higher levels of positive affect intensity (within-person instability); (b) modifications in the characteristics of profiles which come to display higher levels of positive affect intensity (within-sample structural instability); and (c) increases in the size of profiles with higher levels of positive affect intensity (within-sample distributional instability).

Martinent et al. (2013) examined whether the same athletes belonged to the same affect profiles both before and during competition. Interestingly, their results only revealed low to moderate levels of within-person stability, corresponding to $25.33 \%$ for the facilitators, $37.50 \%$ for the high positive affect facilitators, $48.33 \%$ for the high negative affect incapacitators, and $67.47 \%$ for the low affect incapacitators. Similar rates of stability were reported by Martinent and Nicolas (2017a). When the most frequent transitions were considered, some patterns were more frequent than others, suggesting that: (a) more intense affect was harder to maintain; (b) that transitions were more frequent across profiles not differing drastically in terms of valence or intensity; and (c) that a change on the valence 
of the dominant affect tended to be accompanied by a change in direction.

When considering these findings, it is noteworthy that these two investigations considered two sets of drastically different circumstances (before and during competition) during which individuals' affect is known to undergo major transformations (Martinent et al., 2013). As such, these results are unlikely to be directly transposable to the present study of employees followed across a more normative fourmonth period, leading us to expect slightly higher levels of within-person stability than that identified in these previous studies. Yet, the fact that these previous studies found strong evidence of withinsample stability suggests that the same number of profiles (configural similarity) characterized by the same shape (structural similarity) should be identified at both time waves. More precisely:

Hypothesis 3. At the within-sample level, the results will support the configural and structural similarity of the profiles.

Hypothesis 4. The profiles will display high to moderate levels of within-person stability.

Unfortunately, no previous study relied on systematic tests of profile similarity (Morin, Meyer et al., 2016), making it hard to formulate specific expectations related to within-sample stability in terms of variability (dispersion similarity) or profile sizes (distributional similarity). We thus leave as an open research question whether the profiles will demonstrate dispersion and distributional similarity.

\section{Predictors of Affect Profiles}

A third objective of the present study was to assess the predictive role of participants' levels of psychological needs satisfaction and perceptions of their supervisors' autonomy-supportive behaviors, in relation to their likelihood of membership into the various affect profiles. According to selfdetermination theory (Deci \& Ryan, 2000), the satisfaction of the three psychological needs for competence (feelings of effectiveness in one's interactions with the environment), autonomy (feelings of psychological freedom and volition), and relatedness (feelings of connections with others) is seen as a crucial determinant of self-determined behaviors and optimal functioning across domains, including work (Deci, Olafsen, \& Ryan, 2017). Likewise, this theory (Deci \& Ryan, 2000) emphasize the central role of employees' perceptions of being exposed to autonomy-supportive behaviors from their supervisor, which refer to having the impression that their supervisor acknowledges their perspectives and feelings, provides them with a meaningful rationale for doing their job, and emphasizes choice rather than control as another key predictor of optimal functioning (Deci, Connell, \& Ryan, 1989). Despite the established importance of supervisor autonomy support and need satisfaction at work (Gagné \& Deci, 2005), we are not aware of any variable- or person-centered study in which the effects of these variables on the various components of work affect have been systematically considered.

Nevertheless, some studies have considered the effects of supervisor autonomy support on conceptually-related constructs, namely well-being (Gilbert, Dagenais-Desmarais, \& St-Hilaire, 2017), job satisfaction (Gillet, Colombat, Michinov, Pronost, \& Fouquereau, 2013; Gillet, Gagné, Sauvagère, \& Fouquereau, 2013), performance (Kong \& Ho, 2016), and burnout (Kanat-Maymon, Yaakobi, \& Roth, 2018). More generally, results from a recent meta-analysis conducted by Slemp, Kern, Patrick, and Ryan (2018) revealed that supervisor autonomy support was positively associated with well-being, performance, and work engagement, and negatively related to psychological distress, burnout, and stress. Given that supervisors who adopt autonomy-supportive behaviors provide employees with critical information about their work role, and acknowledge their feelings in an empathic manner (Black \& Deci, 2000), it would be logical for supervisor autonomy support to foster positive affect intensity with a facilitative effect on job performance, and to decrease negative affect intensity with a detrimental effect on job performance.

Past research (e.g., Tóth-Király, Bőthe, Orosz, \& Rigó, 2019; Vandercammen, Hofmans, \& Theuns, 2014) has also demonstrated that high levels of relatedness, autonomy, and competence needs satisfaction were related to higher levels of positive affect intensity and performance, and with lower levels of negative affect intensity. Similarly, employees' need satisfaction has been positively related to work engagement (Gillet, Fouquereau, Huyghebaert, \& Colombat, 2015) and job satisfaction (Huyghebaert, Gillet et al., 2018). Being able to feel that one's needs for relatedness, autonomy, and competence are satisfied at work has been previously described as a core psychological resource to support employees' personal optimal functioning and development (Gagné \& Deci, 2005). More specifically, employees who perceive that their job contributes to support their basic psychological needs, are more likely to value their workplace, to invest efforts into their professional activities, to experience positive affect intensity and direction, and to experience lower levels of negative affect 
intensity (Ryan \& Deci, 2017). These considerations lead us to propose the following hypotheses:

Hypothesis 5. Psychological need satisfaction and perceptions of supervisor's autonomysupportive behaviors will predict a greater likelihood of membership into profiles presenting higher levels of positive affect direction with a facilitative effect on job performance.

Hypothesis 6. Psychological need satisfaction and perceptions of supervisor's autonomysupportive behaviors will predict a weaker likelihood of membership into profiles presenting by higher levels of negative affect direction with a detrimental effect on job performance.

\section{Outcomes of Affect Profiles}

A final objective of this research was to document the construct validity of the identified profiles (Meyer \& Morin, 2016) through an investigation of their associations with a series of outcomes, namely turnover intentions, absenteeism, and work-family conflict. These outcomes were selected in part because of the high costs associated with turnover and absenteeism for organizations (Duffield, Roche, Homer, Buchan, \& Dimitrelis, 2014). Moreover, in an era of ever-growing technology and constant connectivity, boundaries between the work and home domains have become blurred, and employees are growing aware of the necessity to disconnect from work in order to protect their psychological health (Huyghebaaert, Fouquereau et al., 2018). Indeed, research has consistently demonstrated the detrimental effects of over-investing the work domain (e.g., Geurts, Kompier, Roxburgh, \& Houtman, 2003) as it takes a toll on workers' private life (i.e., work-family conflict).

Previous studies focusing on the importance of positive and negative affect intensity in understanding employees' attitudes and behaviors at work has been guided by the "symmetrical assumption" that positive affect is beneficial and negative affect is detrimental (Lindebaum \& Jordan, 2012). More precisely, affective events theory (Weiss \& Cropanzano, 1996) suggests that employees' positive and negative affect experiences at work should be associated in such a symmetrical manner with a series of attitudes and behaviors such as work-family conflict, absenteeism, turnover intentions, and performance. Prior variable-centered studies have already supported relations between affect and these outcomes (Gillet, Vallerand, Lafrenière, \& Bureau, 2013; Lloyd, Boer, Keller, \& Voelpel, 2015). For instance, Dong, Seo, and Bartol (2014) showed that positive affect was associated with less pronounced turnover intentions, while negative affect was associated with more pronounced turnover intentions (see Mason \& Griffin, 2003, for similar effects on absenteeism). Indeed, employees tend to pursue or avoid situations in order to maintain their current positive affect and to reduce negative affect (Morris \& Reilly, 1987). When workers experience positive affect, they are likely to remain in their organization to maintain positive affect. In contrast, experiencing negative affect makes it more likely for them to consider withdrawing from their current organization to reduce negative affect (Dong et al., 2014).

Paulson and Leuty (2016) similarly showed that negative affect was related to higher levels of work-family conflict, while the association between positive affect and work-family conflict was not significant (for similar results, see Tement \& Korunka, 2013). The conservation of resources theory (Hobfoll, 2002) proposes that negative affect should be associated with decreased resistance to strain because it interferes with employees' ability to enhance their resources (Frone, 2003). Moreover, Friede and Ryan (2005) argued that employees experiencing higher levels of negative affect tend to describe their work and family situations as being more stressful, leading to higher levels of workfamily conflict. Taken together, these considerations allow us to propose the following hypothesis:

Hypothesis 7. The highest levels of turnover intentions, absenteeism, and work-family conflict will be related to profiles characterized by the lowest levels of positive affect intensity with a detrimental effect on job performance, and to profiles presenting the highest levels of negative affect intensity with a detrimental effect on job performance.

\section{Participants and Procedure}

\section{Method}

After having been informed of the objective of this research and ensured that their participation was entirely voluntary and confidential, participants were invited to complete online questionnaires twice over a period of four months. Participants who agreed to participate were asked to disclose a unique identifier allowing us to link their responses over time while maintaining confidentiality. Overall, 491 individuals $\left(\mathrm{M}_{\text {age }}=45.69 ; S D=8.55\right)$ working in French firefighting centers, including 400 males and 91 females, agreed to participate in this study. Of those, 139 (28.3\%) completed the questionnaires again four months later (Time 2). In total, 202 participants (41.1\%) were professional 
firefighters, 197 were volunteer $^{2}$ firefighters $(40.1 \%)$, and 92 were administrative workers $(18.7 \%)$. On the average, respondents had 17.67 years $(S D=9.62)$ of tenure in their organization and of 6.38 years $(S D=5.44)$ in their position. In terms of education, 175 participants had a university diploma $(35.6 \%)$, 198 had a certificate of vocational training (40.3\%), 109 had a high school diploma (22.2\%), and 9 $(1.8 \%)$ had no diploma.

\section{Measures}

Affect. Positive and negative affect intensity at work was assessed with the Positive and Negative Affect Schedule (Watson et al., 1988), to which a directional assessment procedure was added to assess directionality (PANAS-D; Nicolas et al., 2014). The resulting questionnaire thus includes two 10-item subscales covering negative (e.g., "upset") and positive (e.g., "excited") affect at work for which participants had to rate: (a) the intensity (i.e., the extent to which they generally experience the considered work affect in their job using a 5-point scale ranging from 1- not at all to 5- extremely); and (b) the direction (i.e., the extent to which they generally feel that the considered work affect has a negative, non-significant, or positive effect on their job performance using a 7-point scale ranging from -3- very impairing to +3 - very facilitative). Cronbach's alphas were .82 (Time 1) and .87 (Time 2) for positive affect intensity, .87 (at both Time 1 and Time 2) for negative affect intensity, .90 (Time 1) and .92 (Time 2) for positive affect direction, and .97 (at both Time 1 and Time 2) for negative affect direction.

Supervisor Autonomy Support. Participants' reported their perception of their supervisor's autonomy-supportive behaviors using nine items $(\alpha=.95$ at both Time 1 and 2; e.g., "My supervisor gives me many opportunities to make decisions in my work") from Moreau and Mageau's (2012) questionnaire. Ratings were made on a 7-point scale ("Strongly Disagree" to "Strongly Agree").

Need Satisfaction. A scale developed by Gillet, Rosnet, and Vallerand (2008) and recently validated in the work context (Huyghebaert, Gillet et al., 2018) was used to assess need satisfaction. Five items each were used to assess the satisfaction of the needs for competence ( $\alpha=.80$ at Time 1 and .84 at Time 2; e.g., "I feel like I am able to meet the demands of the tasks that I have to perform"), autonomy ( $\alpha=.86$ at Time 1 and .83 at Time 2; e.g., "I have the opportunity to make decisions about the tasks that I have to perform"), and relatedness ( $\alpha=.75$ at Time 1 and .77 at Time 2; e.g., "I get along well with the people whom I interact with"). Ratings were made on a 7-point scale ("Strongly Disagree" to "Strongly Agree"). Only participant's global levels of need satisfaction across all three needs are used in the analyses. This score was estimated via the global factor of a preliminary bifactor measurement model reported in the online supplements.

Work-Family Conflict. Three items $(\alpha=.91$ at Time 1 and .94 at Time 2; e.g., "Your work schedule makes it difficult for you to fulfil your domestic obligations") from Demerouti, Bakker, and Bulters (2004) were used to assess work-family conflict. Ratings were made on a 7-point scale ("Strongly Disagree" to "Strongly Agree").

Turnover Intentions. Three items $(\alpha=.83$ at Time 1 and .86 at Time 2; e.g., "I often think about resigning") from Becker and Billings (1993) were used to assess turnover intentions. Ratings were made on a 5-point scale ("Strongly Disagree" to "Strongly Agree").

Absenteeism. We relied on a single-item measure (Kessler et al., 2003) to assess absenteeism. On this item, respondents were asked to indicate how many entire work days they missed during the past year because of problems related to their physical or mental health.

\section{Preliminary Measurement Analyses}

\section{Analyses}

The psychometric properties of all measures were verified in the context of preliminary analyses reported in the online supplements. These analyses supported the quality of all measures, and their measurement invariance across time waves (Millsap, 2011). Factor scores, saved from these preliminary analyses in standardized units $(M=0 ; S D=1)$, were utilized as profile indicators, predictors, and outcomes in the main analyses. Although factor scores are unable to provide results completely corrected from measurement errors, their calculation ascribes more weight to more reliable

\footnotetext{
${ }^{2}$ Upon request from a reviewer, we verified whether volunteer or professional firefighters differ from one another in terms of profile membership or measurement. We found no evidence that this distinction predicted profile membership, and found support for the measurement invariance of our affect measure across these two groups of participants. These additional results are available upon request from the authors.
} 
items, thus providing a partial correction for unreliability (Skrondal \& Laake, 2001). Factor scores also preserve the nature of the measurement model, such as its measurement in invariance, something that cannot be done when using scale scores (Morin, Boudrias et al., 2016; Morin, Meyer et al., 2016).

\section{Latent Profile Analyses (LPA)}

Time-specific LPA were first estimated on the basis of the four affect factors. These initial analyses helped us to ascertain whether the number of identified profiles would be similar across time points (i.e., configural similarity). Solutions ranging from one to eight profiles were estimated at each time points, while allowing the means and variances of the affect factors to be freely estimated across profiles (Diallo, Morin, \& Lu, 2016; Morin, Maïano et al., 2011; Peugh \& Fan, 2013). The time-specific LPA solutions selected at each time point were then integrated into a longitudinal LPA model. This longitudinal LPA was used to test the similarity of these LPA solutions across time points based on procedures outlined by Morin, Meyer et al. (2016) and adapted to longitudinal analyses by Morin and Litalien (2017). This sequential procedure starts by verifying if the same number of profiles would be estimated across each measurement occasion (i.e., configural similarity). Equality constraints are then imposed sequentially on the within-profile means (structural similarity), variances (dispersion similarity), and size (distributional similarity).

\section{Latent Transitions Analyses (LTA), Predictors, and Outcomes}

The most similar LPA solution was converted to a LTA in order to assess individual transitions in terms of profile membership (e.g., within-person stability; Collins \& Lanza, 2010; Kam et al., 2016) to which predictors and outcomes were incorporated.

The associations between the time-specific predictors (global levels of need satisfaction and autonomy support) and profile membership were assessed via a multinomial logistic regression function following the direct incorporation of the predictors into the LTA. Four models were contrasted (Ciarrochi, Morin, Sahdra, Litalien, \& Parker, 2017; Gillet, Morin, Huyghebaert et al., 2019). A null effect model was first specified. In this model, associations between the predictors and the profiles were constrained to be zero. In a second model, these associations were estimated freely across time points and Time 1 profiles in order to directly test the effects of the predictors on the profile transitions (i.e., on the likelihood of transitioning into a specific profile at the next time point based on profile membership at the prior time point). A third model also allowed these associations to differ over time, but constrained them to equality across Time 1 profiles. In this model, the predictors were not allowed to predict the profile transitions themselves, but their effects were allowed to change over time. In a fourth model, these associations were constrained to be equal across time points, resulting in a model of predictive similarity.

Time-specific measures of the outcomes (turnover intentions, work-family conflict, and absenteeism) were finally integrated to the LTA in order to assess their relations with the profiles measured at the same time point. Mean-level differences were conducted in a single step (across all pairs of profiles) using the multivariate delta method (Raykov \& Marcoulides, 2004). A second model was then estimated in which the within-profile outcome levels were constrained to equality over time in order to test the explanatory similarity of the solution. All of these models simultaneously included predictor, or outcome, measures taken at the two time points, so that all the relations estimated in relation to Time 2 variables (predictors, outcomes, and profiles) can be considered to be controlled for Time 1 measures of the same variables.

\section{Model Estimation}

All models were estimated with Mplus 8 (Muthén \& Muthén, 2017), using the maximum likelihood robust estimator (MLR). LPA were estimated using 5000 sets of random start values (e.g., Hipp \& Bauer, 2006) allowed 1000 iterations each, and final stage optimization was conducted on the 200 best solutions. These numbers were changed to 10000, 1000, and 500 for the longitudinal LPA and LTA. All longitudinal models were estimated using responses from all respondents $(\mathrm{N}=491)$ rather than using only those who completed both time waves $(\mathrm{N}=139)$. This was made possible with the reliance on Full Information Maximum Likelihood (FIML) procedures (Enders, 2010; Graham, 2009). FIML has been shown to be as effective as multiple imputation for handling missing data, but to have more efficiency, even in the presence of large amounts of missing data (Enders, 2010; Graham, 2009; Jeličič, Phelps, \& Lerner, 2009; Larsen, 2011). The missing at random (MAR) assumptions of FIML make this procedure robust to differences stemming from attrition in relation to any variables included in the models (Enders, 2010; Graham, 2009). 


\section{Model Selection}

The decision of how many profiles to retain at each time point is predicated on multiple sources of information, including a consideration of whether the profiles are meaningful, aligned with theory, and statistically adequate (Marsh et al., 2009; Morin, 2016; Muthén, 2003). In addition, statistical indicators (McLachlan \& Peel, 2000) can be consulted. Thus, a lower value on the Akaïke Information Criterion (AIC), Consistent AIC (CAIC), Bayesian Information Criterion (BIC), and sample-size Adjusted BIC (ABIC) indicate better fitting models. Likewise, statistically significant p-values on the adjusted Lo, Mendell and Rubin's (2001) Likelihood Ratio Test (aLMR), and Bootstrap Likelihood Ratio Test (BLRT) suggest better fit relative to a model with one fewer profile.

Statistical research has shown the BIC, CAIC, ABIC, and BLRT, but not the AIC and aLMR, to be efficient at helping to identify the number of latent profiles (Diallo, Morin, \& Lu, 2016, 2017; Henson, Reise, \& Kim, 2007; Nylund, Asparouhov, \& Muthén, 2007; Peugh \& Fan, 2013; Tein, Coxe, $\&$ Cham, 2013). For this reason, the AIC and aMLR will not be used for purposes of model comparison and selection, but will still be reported for purposes of transparency. A recent simulation study (Diallo et al., 2017) suggests to favor the BIC and CAIC when the entropy (an indice of classification accuracy) is high (e.g., $\geq .800$ ), but the ABIC and BLRT when it is low (e.g., $\leq .600$ ). These tests all present a strong sample size dependency (Marsh et al., 2009). For this reason, they often fail to converge on a specific number of profiles. When this happens, it is usually recommended to rely on a graphical display of these indicators, referred to as an elbow plot, in which the observation of a plateau may help to pinpoint the optimal solution (Morin, Maïano et al., 2011). For tests of profile similarity and model comparisons, the CAIC, BIC, and ABIC can be used to contrast alternative models. Each form of profile similarity can be considered to be supported as long as at least two of these indices decrease following the integration of equality constraints (Morin, Meyer et al., 2016).

\section{Results}

The results from the time-specific LPA are reported in Table 1. Across time waves, the entropy values associated with the solutions including three profiles and more are all relatively high (.745 and above), suggesting that more attention should be given to the CAIC and BIC. The elbow plots presenting a graphical display of the information criteria can be found in Figures S1 and S2 of the online supplements, and reveal a first inflection point at three profiles, and a second one at five profiles. This second inflection point was particularly marked for the CAIC and BIC which almost reached a perfect plateau after five profiles. Solutions including three to five profiles were thus more carefully considered. Importantly, this careful examination revealed a high level of similarity in the matching solutions estimated across time points, thus already providing evidence of longitudinal similarity. Moreover, this examination revealed that up to five profiles, each added profile proved to be meaningful across time points. In contrast, the addition of a sixth profile led to the arbitrary separation of an existing profile in smaller ones. For these reasons, we decided to retain the fiveprofile solution at both time waves (i.e., configural similarity). The classification accuracy of this solution is reasonably high, as illustrated by an entropy value of .842 at Time 1 and .759 at Time 2 .

The results from all longitudinal solutions are reported in Table 2. The results from the longitudinal LPA analyses further support the structural (lower CAIC and BIC values relative to the configural model), but not the dispersion, similarity of the solution over time. We thus investigated the possibility of retaining a solution of partial dispersion similarity by relaxing the equality constraints on the within-profile variability of the largest profile over time. Indeed, this specific profile was evidencing a reduction in the degree of within-profile variability at Time 2, consistent with the lowest sample size available at this second measurement point. The results supported this model of partial dispersion similarity (lower CAIC and BIC values relative to the structural model). Starting from this model, the next model (distributional similarity) was not supported by the data. Given the impossibility of conducting tests of partial distributional similarity, the model of partial dispersion similarity was thus retained. This model is graphically represented in Figure 1, and detailed parameter estimates from this model can be consulted in Table S6 of the online supplements.

Profile 1 was characterized by moderately high levels of positive affect intensity, low levels of negative affect intensity, moderate levels of positive affect direction, and high levels of negative affect direction. This profile, which was labelled "Low Negative Affect Facilitators", corresponded to 9.83\% of the sample at Time 1, but only to $1.54 \%$ of the sample at Time 2. Profile 2 was characterized by moderately low levels of positive affect intensity, moderate levels of negative affect intensity, very 
low levels of positive affect direction, and high levels of negative affect direction. This "Moderately Low Positive Affect Incapacitators" profile corresponded to 5.56\% of the sample at Time 1, but only to $1.87 \%$ of the sample at Time 2. Profile 3 presented high levels of positive affect intensity and direction, coupled with moderately low levels of negative affect intensity and direction. This "High Positive Affect Facilitators" profile corresponded to $22.48 \%$ of the participants at Time 1 and to a similar proportion of $21.36 \%$ of the sample at Time 2. Profile 4 was characterized by low levels of positive affect intensity and direction, high levels of negative affect intensity, and moderate levels of negative affect direction. This "Very Low Positive Affect Incapacitators" profile corresponded to $18.41 \%$ of the participants at Time 1 and to a similar proportion of $17.23 \%$ of the sample at Time 2 . Finally, Profile 5 presented moderate levels of positive and negative affect intensity and direction. This "Normative" profile was also the largest at both time points, corresponding to $43.73 \%$ of the participants at Time 1 and to $58.00 \%$ of them at Time 2 .

\section{Latent Transitions}

The transition probabilities from the LTA solution (estimated from the model of partial dispersion similarity) are reported in Table 3. Examination of these results shows that membership into Profiles 3 (High Positive Affect Facilitators; stability of 98.9\%), 4 (Very Low Positive Affect Incapacitators; stability of $98.3 \%$ ), and 5 (Normative; stability of $95.8 \%$ ) are very stable over time and essentially unchanged. In contrast, membership into the two negative affect facilitator profiles (Profile 1: Stability of $9.3 \%$; Profile 2: Stability of 3.5\%), which both also substantially reduced in size over time, is mostly unstable over time. When transitions occur for participants initially corresponding to Profile 1 (Low Negative Affect Facilitators), they mainly involve Profile 5 (Normative; 67.2\%), although some members of Profile 1 also transition to other facilitator profiles (Profile 3, High Positive Affect Facilitators: 19.0\%; and Profile 2, Moderately Low Positive Affect Incapacitators: 4.5\%). Finally, when transitions occur for participants initially corresponding to Profile 2 (Moderately Low Positive Affect Incapacitators), they mainly involve Profiles 4 (Very Low Positive Affect Incapacitators; $76.0 \%$ ), although some members of Profile 2 also transition to Profile 5 (Normative; 20.5\%).

\section{Predictors}

Before proceeding to the integration of the predictors, we initially investigated the need to incorporate participants' demographic characteristics (age, sex, and education level) as controlled variables in the upcoming analyses. Indeed, prior studies have shown that these dimensions may be significantly related to positive and negative affect intensity and direction (e.g., Chan, Gerhardt, \& Feng, 2019; Gomez-Baya, Mendoza, Paino, \& Gillham, 2017). As shown in Table 2, the results from the analyses involving these demographic predictors supported the null effects model (i.e., this model had the lowest values on all information criteria), consistent with a lack of effect of demographic variables. This conclusion was also supported by the parameter estimates associated with these models. For these reasons, demographic controls were not retained for the next stages of analyses.

As shown in Table 2, when the a priori predictors were then included into the model, the results supported the model of predictive similarity, which resulted in the lowest values for the CAIC, BIC, and ABIC. These results thus support the equivalence of the predictions across time periods and a lack of effects of the predictors on specific transitions across profiles. The results from this model of predictive similarity are reported in Table 4 . No statistically significant association was noted between profile membership and perceptions of supervisor autonomy-supportive behaviors. However, results revealed clear and systematic associations between global levels of need satisfaction and membership into most profiles. Thus, higher levels of global need satisfaction were related to a higher likelihood of membership into: (a) Profiles 1 (Low Negative Affect Facilitators) and 3 (High Positive Affect Facilitators) relative to Profile 5 (Normative); (b) Profiles 1 (Low Negative Affect Facilitators), 2 (Moderately Low Positive Affect Incapacitators), and 3 (High Positive Affect Facilitators) relative to Profile 4 (Very Low Positive Affect Incapacitators); and (c) Profile 1 (Low Negative Affect Facilitators) relative to Profile 2 (Moderately Low Positive Affect Incapacitators). Higher global need satisfaction levels were also associated with a reduced likelihood of membership into: (a) Profiles 2 (Moderately Low Positive Affect Incapacitators) and 4 (Very Low Positive Affect Incapacitators) relative to Profile 5 (Normative), and (b) Profile 2 (Moderately Low Positive Affect Incapacitators) relative to Profile 3 (High Positive Affect Facilitators).

\section{Outcomes}

The model of explanatory similarity, in which within-profile outcome levels were constrained to 
equality over time, resulted in lower values for all information criteria (see Table 2) and was thus retained. The detailed results from this model appear in Table 5 and revealed systematic differences across profiles. The highest levels of turnover intentions were associated with Profile 4 (Very Low Positive Affect Incapacitators), followed by 2 (Moderately Low Positive Affect Incapacitators), then 5 (Normative), and finally 1 (Low Negative Affect Facilitators) and 3 (High Positive Affect Facilitators) which did not differ from one another. Profile 4 (Very Low Positive Affect Incapacitators) was related to higher levels of work-family conflict than 1 (Low Negative Affect Facilitators) and 3 (High Positive Affect Facilitators) which did not differ from one another. Profile 5 (Normative) was also linked to higher levels of work-family conflict than 3 (High Positive Affect Facilitators). In terms of absenteeism, Profile 1 (Low Negative Affect Facilitators) was associated with lower levels than 2 (Moderately Low Positive Affect Incapacitators). Profiles 1 (Low Negative Affect Facilitators) and 2 (Moderately Low Positive Affect Incapacitators) were also related to lower levels of absenteeism than 3 (High Positive Affect Facilitators), 4 (Very Low Positive Affect Incapacitators), and 5 (Normative). Finally, levels of absenteeism were lower in Profile 3 (High Positive Affect Facilitators) relative to 4 (Very Low Positive Affect Incapacitators).

\section{Discussion}

Prior research has demonstrated that four components of work affect (i.e., positive affect intensity and direction, negative affect intensity and direction) presented moderate to strong inter-correlations while presenting well-differentiated relations to various outcome measures (e.g., Martinent \& Nicolas, 2017a; Martinent et al., 2013). Yet, very little attention has been devoted to identifying the most commonly occurring combinations of these four components among specific profiles of employees. The adoption of a person-centered approach is naturally suited to the consideration of positive and negative affect intensity and direction configurations among different profiles of workers, and how these combinations relate to predictors and outcomes.

\section{Characteristics of Employees' Affect Profiles}

Supporting Hypothesis 1, the results led to the identification of five affect profiles among a sample of French employees: (a) Low Negative Affect Facilitators (moderately high positive affect intensity, low negative affect intensity, moderate positive affect direction, and high negative affect direction); (b) Moderately Low Positive Affect Incapacitators (moderately low positive affect intensity, moderate negative affect intensity, very low positive affect direction, and high negative affect direction); (c) High Positive Affect Facilitators (high positive affect intensity and direction, and moderately low negative affect intensity and direction); (d) Very Low Positive Affect Incapacitators (low positive affect intensity and direction, high negative affect intensity, and moderate negative affect direction); and (e) Normative (moderate positive and negative affect intensity and direction).

A noteworthy observation lies in the identification of a Normative profile, representing $43.73 \%$ of the participants at Time 1 and $58.00 \%$ of them at Time 2. The label Normative was retained to reflect the fact that this profile not only characterized the majority of employees, but also reflected a subpopulation of employees whose levels of positive and negative affect intensity/direction are close to average. This profile suggested that these four components of work affect display a strong level of balance across each dimension, and thus can be inferred to rely on effective affect regulation strategies. This profile might present at least some degree of specificity to the specific occupational group considered in the present study. Indeed, firefighters (just like healthcare workers) are known to be particularly efficient at regulating their affect when facing the variety of stressful and/or difficult situations that characterize their daily work activities (e.g., individual caring, managing urgent incidents; Sandrin, Gillet, Fernet, Leloup, \& Depin- Rouault, 2019). Indeed, the nature of the relationship between firefighters and the individuals needing their help is seen as a central job component in this profession, and one that requires substantial dedication, emotional engagement, and commitment. Emotional labor is also seen as central, particularly given the emotional, cognitive, and/or physical vulnerability of persons who need help (Fouquereau, Morin, Lapointe, Mokounkolo, \& Gillet, 2019). However, despite this likely specificity, this Normative profile was also acknowledged as a possibility in the introduction and is consistent with previous reports of high correlations between positive and negative affect intensity and direction (Nicolas et al., 2014). Morin, Boudrias et al. (2016) also identified a Normative profile presenting average levels of global psychological health and average levels on all specific components of psychological well-being and distress. Similar normative profiles have been identified in research on work-related well-being 
(Morin, Boudrias et al., 2017), need satisfaction (Gillet, Morin, Choisay, \& Fouquereau, 2019), and engagement (Gillet, Caesens, Morin, \& Stinglhamber, 2019).

In addition, and supporting Hypothesis 2, characteristics of the High Positive Affect Facilitators are very similar to those identified in past sport-related research (Martinent et al., 2013). In contrast, two additional profiles were not fully expected by our hypotheses which simply suggested the presence of a generic facilitator profile. These profiles were characterized by an imbalance in levels of positive and negative affect intensity and direction: Profiles 1 "Low Negative Affect Facilitators" and 2 "Moderately Low Positive Affect Incapacitators". It is noteworthy that these two profiles were however relatively rare (Profile 1: $9.83 \%$ at Time 1, but only $1.54 \%$ at Time 2, and Profile 2: $5.56 \%$ at Time 1, but only $1.87 \%$ at Time 2). In addition, and against our expectations, we found no evidence of profiles directly matching the Low Affect Incapacitators and Negative Affect Incapacitators suggested by previous studies, but rather identified Very Low Positive Affect Incapacitators. It is likely that these divergences can be explained by the highly distinct nature of the samples considered in these previous investigations (e.g., athletes in Martinent et al., 2013) relative to the present sample of employees. More specifically, these divergences suggest that the work context is likely to generate distinct affect configurations than the athletic context, and reinforce the need for additional person-centered investigations to document the generalizability of our findings. For instance, the approach developed by Morin, Meyer et al. (2016) could also be used to assess the similarity of profiles across employees from different professional groups (e.g., nurses, teachers, managers). Such evidence of generalizability would support the utility of intervention strategies based on person-centered results.

\section{Longitudinal Stability and Changes in Employees' Affect Profiles}

When considering within-sample stability, our results supported Hypothesis 3 in revealing that the same number of profiles (configural similarity), presenting the same affect structure (structural similarity), could be identified across a time interval of four-months. They also enriched our understanding of profile stability by revealing that the degree of interpersonal differences among members of specific profiles (dispersion similarity) and the relative sizes of the profiles (distributional similarity) changed over this four-month period.

When considering within-person stability, our results only partially supported Hypothesis 4, in relation to a subset of profiles. More precisely, our results revealed that membership into three (High Positive Affect Facilitators, Very Low Positive Affect Incapacitators, and Normative) of the five affect profiles remained very stable over four months (with stability rates ranging from $95.8 \%$ to $98.9 \%$ ). These results showed slightly higher levels of within-person stability than that identified in past studies conducted in the sport context (Martinent et al., 2013; Martinent \& Nicolas, 2017a). It is true that this stability could possibly reflect, at least partially, the relatively short time interval that was considered here (four months). Yet, the fact that we found evidence for a substantial level of withinsample and within-person changes suggests that the time interval was sufficient to study change.

Indeed, results showed that within-person changes were far more frequent over this same fourmonth period for the Low Negative Affect Facilitators and Moderately Low Positive Affect Incapacitators (stability of $9.3 \%$ and stability of $3.5 \%$, respectively). More specifically, participants initially corresponding to Profile 2 (Moderately Low Positive Affect Incapacitators) mainly transitioned to Profile 4 (Very Low Positive Affect Incapacitators; 76.0\%), whereas the reverse was not true. These two profiles are characterized by similarly low levels of positive affect intensity and direction but different levels of negative affect intensity and direction. It is thus possible to maintain similarly low positive affect with a negative effect on job performance over time but, when this occurs, it is accompanied by changes in negative affect intensity (moderate to high levels) and direction (high to moderate levels). When considering these results, it is important to remember that few employees are characterized by the two most unstable profiles over time (only $1.54 \%$ of the sample at Time 2 for the Low Negative Affect Facilitators and only 1.87\% of the sample at Time 2 for the Moderately Low Positive Affect Incapacitators), suggesting that it is extremely hard to maintain over time an affect profile characterized by a high level of negative affect direction (i.e., Facilitators). This observation matches previous results showing that the physiological changes associated with the experience of negative affect can be beneficial for short-term decisive actions, but harmful the longterm (Sapolsky, 1999).

\section{Predictors of Employees' Affect Profiles}

The present study was also designed to investigate the role of employees' psychological need 
satisfaction and perceptions of supervisor autonomy support in the prediction of profile membership. To the best of our knowledge, no work-related research has yet sought to identify the factors involved in the development of affect profiles. Our results first revealed that higher levels of global need satisfaction were important for profiles characterized by moderate to high levels of positive affect intensity and direction, and by low levels of negative affect intensity. It is noteworthy that higher levels of global need satisfaction were also related to a higher likelihood of membership into Profile 2 (Moderately Low Positive Affect Incapacitators) relative to Profile 4 (Very Low Positive Affect Incapacitators). These two profiles were characterized by similar levels of positive affect intensity and direction but the Very Low Positive Affect Incapacitators displayed higher levels of negative affect intensity. These results supported Hypotheses 5 and 6, and match those from past studies showing psychological need satisfaction to foster positive affect intensity and performance, and to decrease negative affect (Tóth-Király et al., 2019; Vandercammen et al., 2014). This interpretation is consistent with the theoretical perspective that psychological needs represents basic nutrients that fuel individuals' growth and facilitate optimal functioning (Deci \& Ryan, 2000).

Finally, participants' perceptions of their supervisor autonomy-supportive behaviors were not significantly related to profile membership. Contrary to those found by Slemp et al. (2018) in their recent meta-analysis (see also Gillet, Colombat et al., 2013; Gillet, Gagné et al., 2013), these results suggest that supervisor autonomy-supportive behaviors did not predict workers' affect. It is possible that autonomy-supportive behaviors implemented more formally at higher levels in the organization may yield greater benefits for employees than more proximal autonomy-supportive behaviors implemented by the supervisor (Liu, Chen, \& Yao, 2011), and that the efficacy of supervisor's behaviors might depend on the frequency of employees' contacts with their supervisors.

Liu, Zhang, Wang, and Lee (2011) also suggested that the interpretation by an employee of supervisor autonomy support and consequently his/her work affect may depend on the idiosyncrasy of this support relative to the levels of autonomy support received by other workers. Thus, perceived equity in terms of autonomy support may moderate the relations between employees' perceptions of supervisor autonomy support and their affect, such that the association between perceived supervisor autonomy support and positive affect intensity might be stronger when equity is greater or more favorable to the targeted employee. In addition, a favorable level of inequity (when an employee perceived being exposed to more desirable practices than his or her colleagues) might indicates more idiosyncratic leader-member relationships (Boies \& Howell, 2006), which leads an employee to value this support more and thus strengthens the positive link between autonomy support and positive affect intensity. It would be interesting for future research to devote more attention to unpacking the various mechanisms involved in autonomy-supportive behaviors, and to do so while using a greater variety of autonomy support measures (Slemp et al., 2018). Moreover, future research should examine whether additional time-changing characteristics might also influence profile membership such as, perhaps, job crafting, autonomous and controlled motivations, and workaholism (e.g., Gillet, Morin, Cougot, \& Gagné, 2017; Gillet, Vallerand et al., 2013).

\section{Outcomes of Employees' Affect Profiles}

A final objective was to document the construct validity of the identified affect profiles by assessing their relations with a series of outcomes (turnover intentions, work-family conflict, and absenteeism). The affect profiles identified in this study presented well-differentiated associations with the various outcomes considered in the present study that also appeared to generalize over time. Specifically, the employees characterized by low to vet low levels of positive affect intensity and direction, coupled with high levels of negative affect intensity with a neutral effect on job performance (Very Low Positive Affect Incapacitators) were found to be present the highest levels of turnover intentions, work-family conflict, and absenteeism. Profile 2 (Moderately Low Positive Affect Incapacitators), characterized by similarly low levels of positive affect intensity and direction, was also associated with high levels of turnover intentions and work-family-conflict. In contrast, Profile 3 (High Positive Affect Facilitators), characterized by high levels of positive affect intensity with a facilitative effect on job performance, was associated with the lowest levels of turnover intentions. These results supported Hypothesis 7 and affective events theory's propositions in demonstrating the positive implications of positive affect intensity and the detrimental effects of negative affect intensity (Weiss \& Cropanzano, 1996). These results also match those from previous work-related studies which found that low levels of positive affect intensity and high levels of negative affect intensity 
were particularly harmful for employees (Dong et al., 2014; Paulson \& Leuty, 2016).

It is noteworthy that Profile 4 (Very Low Positive Affect Incapacitators) was associated with worse outcomes (higher levels of turnover intentions, work-family conflict, and absenteeism) than Profile 2 (Moderately Low Positive Affect Incapacitators). These two profiles are characterized by similar levels of positive affect intensity and direction. Nevertheless, some differences between these two profiles can be observed. First, Profile 2 (Moderately Low Positive Affect Incapacitators) was characterized by moderately low levels of positive affect intensity and very low levels of positive affect direction, whereas Profile 4 (Very Low Positive Affect Incapacitators) was characterized by very low levels of positive affect intensity and direction. Then, they also differed in terms of negative affect as Profile 2 (Moderately Low Positive Affect Incapacitators) was characterized by moderate levels of negative affect intensity and high levels of negative affect direction, whereas Profile 4 (Very Low Positive Affect Incapacitators) was characterized by high levels of negative affect intensity and moderate levels of negative affect direction. These results suggest that these differences in turnover intentions, workfamily conflict, and absenteeism across profiles may be explained by the higher levels of negative affect intensity (and to a lower extent by the lower levels of positive affect intensity) that characterize the Very Low Positive Affect Incapacitators. They are aligned with findings from prior studies showing that negative affect is associated with detrimental outcomes (Weiss \& Cropanzano, 1996).

Furthermore, and contrary to our expectations, the High Positive Affect Facilitators presented higher levels of absenteeism than the Moderately Low Positive Affect Incapacitators. These differences suggest that moderate levels of negative affect intensity with a facilitative effect on job performance may help to offset the negative effects of a low level of positive affect intensity coupled with a low level of positive affect direction. These results match those from prior studies showing than negative affect intensity is more strongly related to withdrawal behaviors than positive affect (Iverson \& Deery, 2001). More generally, our results reinforce the need to consider possible synergistic relations between affect, and support the added-value of a joint consideration of positive and negative affect intensity and direction.

Finally, it could have been anticipated that the Normative profile would present lower levels of turnover intentions, work-family conflict, and absenteeism than Profile 2 (Moderately Low Positive Affect Incapacitators) due to their apparently greater ability to regulate their affect. However, this is not what was observed in our results. Indeed, levels of work-family conflict observed in the Normative profile could not be differentiated from those observed among Moderately Low Positive Affect Incapacitators. Likewise, Moderately Low Positive Affect Incapacitators presented lower levels of absenteeism than members of the Normative profile. These results suggest that the presence of balanced, or well-regulated, levels of affect yield benefits in terms of limiting turnover intentions, but not in terms of work-family conflict and absenteeism. More generally, our results suggest that the combined effects of positive and negative affect intensity and direction may differ as a function of the outcomes under study. This observation reinforces the importance for future research to incorporate a broader range of desirable (such as organizational citizenship behaviors) and undesirable (such as counterproductive behaviors) outcomes to better understand the mechanisms at play in these differential effects.

\section{Limitations and Directions for Future Research}

Limitations have to be kept in mind when considering the implications of the present results. First, the present study relied on self-report measures, which could be impacted by self-report biases and social desirability. It would be highly informative for future studies to expand on the current results using more objective measures (e.g., physiological measures of stress, official turnover data), coupled with informant (e.g., supervisors, colleagues) reports of work engagement and job performance. Second, we used a single-item to assess absenteeism, which could explain why the associations between affect profiles and this outcome are slightly different from those with the other outcomes. When compared to multi-item measures, single-item measures tend to be more unreliable and to provide a more limited content coverage. For this reason, it would be interesting to seek to replicate the results from the current study with more solid measurement scales and objective absenteeism data. It would also be informative in future research to further explore the nature (e.g., planned, unplanned) and/or cause (e.g., personal illness, injury) of absenteeism in relation with employees' affect profiles. Third, our treatment of the covariables as either predictors (i.e., need satisfaction and autonomy support) or outcomes (i.e., turnover intentions, work-family conflict, and absenteeism) was based on 
theoretical considerations (Meyer \& Morin, 2016). Despite the fact that this approach allowed us to rule out the possible role of predictors in specific profile transitions, our design and limitations of current analytical possibilities made it impossible to rule out the possibility of spuriousness, reverse causality or reciprocity, nor the possibility that profile transitions could impact changes in outcome levels. Upcoming longitudinal research should adopt alternative methods allowing for a clearer disaggregation of the true directionality of the associations among predictors, outcomes, and profiles.

Fourth, this study relied on a relatively short time interval (four months), which might have accentuated profile stability relative to longer time intervals (e.g., one year). It would be interesting for future research to more precisely assess variations in terms of profile stability and changes that occur over longer, and shorter, time intervals. Finally, the present research relied on a convenient sample of French firefighters with a high attrition rate. Future research is needed to examine the extent to which our results would emerge in employees from different professions, and living in different countries. Importantly, although the reliance on FIML allowed us to work using all participants who participated in the study rather than the subsample who completed both time waves, attrition remains important, and thus calls into question the true generalizability of some of our results. More precisely, our reliance on rigorous tests of profile similarity allows us to be relatively confident regarding the extent to which the profiles estimated at Time $1(n=491)$ replicated the profiles estimated at Time $2(n=$ 139). Likewise, the time-specific associations with predictors and outcomes were also found to be replicated across time points. However, more tentative are the conclusions regarding within-person profile stability (i.e., the over-time transitions) as information available to estimate those could only be provided from the restricted sample who completed the two time points. In addition, despite the fact that FIML relies on missing at random assumption, thus allowing missing values to be a function of all variables included in the model (including the variables themselves at a previous time point), they are not immune to attrition process caused by unmeasured variables. For this reason, future research would do well to try and replicate our results in studies where attrition rates are minimized.

\section{Practical Implications}

Despite these limitations and pending replication, our results suggest that managers should be attentive to employees displaying low to very low levels of positive affect intensity and direction, and high levels of negative affect intensity (Very Low Positive Affect Incapacitators). Indeed, in our study, these workers who appeared to be dominated by negative affect but incapacitated by positive affect, appeared to be at risk for multiple difficulties (e.g., turnover intentions). The present findings also suggested that promoting psychological need satisfaction may help to enhance employees' positive affect intensity with a facilitative effect on job performance and to decrease their negative affect intensity, in turn leading to less difficulties (e.g., lower levels of work-family conflict and turnover intentions). In the literature, numerous studies have shown positive associations between perceived organizational support, psychological need satisfaction, and well-being (Gillet, Colombat et al., 2013; Gillet, Gagné et al., 2013). In line with these findings, having organizations providing higher levels of support might lead to a greater likelihood of membership into the most desirable profile (High Positive Affect Facilitators). Obviously, future research would be need to ascertain this suggestion.

Practitioners and human resources managers should try to promote employees' autonomous motivation in the workplace to increase their positive affect and to reduce their negative affect (Gillet, Vallerand et al., 2013). Among ways to do this, top management could reduce employee work overload and promote justice and fairness in terms of policies and rewards distribution (Gagné \& Deci, 2005). Interestingly, Sandrin, Gillet, Fernet, Leloup, and Depin- Rouault (2019) have also shown that by decreasing firefighters' workload, it was possible to maximize the positive effects of their work autonomous motivation on their well-being and performance.

\section{References}

Beaton, R., Murphy, S., \& Pike, K. (1996). Work and nonwork stressors, negative affective states and pain complaints among firefighters and paramedics. International Journal of Stress Management, 3, 223-237.

Becker, T.E., \& Billings, R.S. (1993). Profiles of commitment: An empirical test summary. Journal of Organizational Behavior, 14, 177-190.

Black, A.E., \& Deci, E.L. (2000). The effects of instructors' autonomy support and students' autonomous motivation on learning organic chemistry: A self-determination theory perspective. Science Education, 84, 740-756. 
Boies, K., \& Howell, J.M. (2006). Leader-member exchange in teams: An examination of the interaction between relationship differentiation and mean LMX in explaining team-level outcomes. Leadership Quarterly, 17, 246-257.

Cash, M.L., \& Gardner, D. (2011). Cognitive hardiness, appraisal and coping: Comparing two transactional models. Journal of Managerial Psychology, 26, 646-664.

Chan, M.H.-m., Gerhardt, M., \& Feng, X. (2019). Measurement invariance across age groups and over 20 years' time of the Negative and Positive Affect Scale (NAPAS). European Journal of Psychological Assessment. Advance online publication. https://doi.org/10.1027/10155759/a000529

Ciarrochi, J., Morin, A.J.S., Sahdra, B.K., Litalien, D., \& Parker, P.D. (2017). A longitudinal personcentered perspective on youth social support: Relations with psychological wellbeing. Developmental Psychology, 53, 1154-1169.

Collins, L.M., \& Lanza, S.T. (2010). Latent class and latent transition analysis: With applications in the social, behavioral, and health sciences. New York, NY: Wiley.

Daniels, K., Glover, J., \& Mellor, N. (2014). An experience sampling study of expressing affect, daily affective well-being, relationship quality, and perceived performance. Journal of Occupational and Organizational Psychology, 87, 781-805.

Deci, E.L., \& Ryan, R.M. (2000). The "what" and "why" of goal pursuits: Human needs and the selfdetermination of behavior. Psychological Inquiry, 11, 227-268.

Deci, E.L., Connell, J.P., \& Ryan, R.M. (1989). Self-determination in a work organization. Journal of Applied Psychology, 74, 580-590.

Deci, E.L., Olafsen, A.H., \& Ryan, R.M. (2017). Self-determination theory in work organizations: The state of a science. Annual Review of Organizational Psychology and Organizational Behavior, 4, $19-43$.

Demerouti, E., Bakker, A.B., \& Bulters, A.J. (2004). The loss spiral of work pressure, work-home interference and exhaustion: Reciprocal relations in a three-wave study. Journal of Vocational Behavior, 64, 131-149.

Diallo, T.M.O, Morin, A.J.S., \& Lu, H. (2016). Impact of misspecifications of the latent variancecovariance and residual matrices on the class enumeration accuracy of growth mixture models. Structural Equation Modeling, 23, 507-531.

Diallo, T.M.O, Morin, A.J.S., \& Lu, H. (2017). The impact of total and partial inclusion or exclusion of active and inactive time invariant covariates in growth mixture models. Psychological Methods, 22, 166-190.

Dong, Y., Seo, M.-G., \& Bartol, K.M. (2014). No pain, no gain: An affect-based model of developmental job experience and the buffering effects of emotional intelligence. Academy of Management Journal, 57, 1056-1077.

Duffield, C.M., Roche, M.A., Homer, C., Buchan, J., \& Dimitrelis, S. (2014). A comparative review of nurse turnover rates and costs across countries. Journal of Advanced Nursing, 70, 2703-2712.

Enders, C.K. (2010). Applied missing data analysis. New York, NY: Guilford.

Ferreira, A.I., da Costa Ferreira, P., Cooper, C.L., \& Oliveira, D. (2019). How daily negative affect and emotional exhaustion correlates with work engagement and presenteeism-constrained productivity. International Journal of Stress Management, 26, 261-271.

Fouquereau, E., Morin, A.J.S., Lapointe, E., Mokounkolo, R., \& Gillet, N. (2019). Emotional labor profiles: Associations with key predictors and outcomes. Work \& Stress, 33, 268-294.

Fredrickson, B.L. (2014). Positive emotions: The good, the bad, the inert, and the complicated. In J. Gruber \& J.T. Moskowitz (Eds.), Positive emotion: Integrating the light sides and dark sides (pp. 535-538). New York, NY: Oxford University Press.

Friede, A., \& Ryan, A.M. (2005). The importance of the individual: How self-evaluations influence the work-family interface. In E.E. Kossek \& S.J. Lambert (Eds.), Work and life integration: Organizational, cultural, and individual perspectives (pp. 193-209). Mahwah, NJ: Lawrence Erlbaum.

Frone, M.R. (2003). Work-family balance. In J.C. Quick \& L.E. Tetrick (Eds.), Handbook of occupational health psychology (pp. 143-162). Washington, DC: American Psychological Association. 
Gable, P.A., Poole, B.D., \& Harmon-Jones, E. (2015). Anger perceptually and conceptually narrows cognitive scope. Journal of Personality and Social Psychology, 109, 163-174.

Gagné, M., \& Deci, E.L. (2005). Self-determination theory and work motivation. Journal of Organizational Behavior, 26, 331-362.

Gardner, D., \& Fletcher, R. (2009). Demands, appraisal, coping and outcomes: Positive and negative aspects of occupational stress in veterinarians. International Journal of Organizational Analysis, $17,268-284$.

George, J.M. (1996). Trait and state affect. In K.R. Murphy (Ed.), Individual differences and behavior in organizations (pp. 145-171.) San Francisco, CA: Jossey-Bass.

Geurts, S.A.E., Kompier, M.A.J., Roxburgh, S., \& Houtman, I.L.D. (2003). Does work-home interference mediate the relationship between workload and well-being? Journal of Vocational Behavior, 63, 532-559.

Gilbert, M.-H., Dagenais-Desmarais, V., \& St-Hilaire, F. (2017). Transformational leadership and autonomy support management behaviors: The role of specificity in predicting employees' psychological health. Leadership \& Organization Development Journal, 38, 320-332.

Gillet, N., Caesens, G., Morin, A.J.S., \& Stinglhamber, F. (2019). Complementary variable- and person-centered approaches to the dimensionality of work engagement: A longitudinal investigation. European Journal of Work and Organizational Psychology, 28, 239-258.

Gillet, N., Colombat, P., Michinov, E., Pronost, A.-M., \& Fouquereau, E. (2013). Procedural justice, supervisor autonomy support, work satisfaction, organizational identification, and job performance: The mediating role of need satisfaction and perceived organizational support. Journal of Advanced Nursing, 69, 2560-2571.

Gillet, N., Fouquereau, E., Huyghebaert, T., \& Colombat, P. (2015). The effects of job demands and organizational resources through psychological need satisfaction and thwarting. The Spanish Journal of Psychology, 18, 1-19.

Gillet, N., Gagné, M., Sauvagère, S., \& Fouquereau, E. (2013). The role of supervisor autonomy support, organizational support, and autonomous and controlled motivation in predicting employees' satisfaction and turnover intentions. European Journal of Work and Organizational Psychology, 22, 450-460.

Gillet, N., Morin, A.J.S., \& Reeve, J. (2017). Stability, change, and implications of student motivation profiles: A latent transition analysis. Contemporary Educational Psychology, 51, 222-239.

Gillet, N., Morin, A.J.S., Choisay, F., \& Fouquereau, E. (2019). A person-centered representation of basic need satisfaction balance at work. Journal of Personnel Psychology, 18, 113-128.

Gillet, N., Morin, A.J.S., Cougot, B., \& Gagné, M. (2017). Workaholism profiles: Associations with determinants, correlates, and outcomes. Journal of Occupational and Organizational Psychology, 90, 559-586.

Gillet, N., Morin, A.J.S., Huyghebaert, T., Burger, L., Maillot, A., Poulin, A., \& Tricard, E. (2019). University students' need satisfaction trajectories: A growth mixture analysis. Learning \& Instruction, 60, 275-285.

Gillet, N., Rosnet, E., \& Vallerand, R.J. (2008). Développement d'une échelle de satisfaction des besoins fondamentaux en contexte sportif. Canadian Journal of Behavioural Science, 40, 230-237.

Gillet, N., Vallerand, R.J., Lafrenière, M.-A.K., \& Bureau, J.S. (2013). The mediating role of positive and negative affect in the situational motivation-performance relationship: A test of the selfdetermination and broaden-and-build theories. Motivation and Emotion, 37, 465-479.

Gomez-Baya, D., Mendoza, R., Paino, S., \& Gillham, J.E. (2017). A two-year longitudinal study of gender differences in responses to positive affect and depressive symptoms during middle adolescence. Journal of Adolescence, 56, 11-23.

Graham, J.W. (2009). Missing data analysis: Making it work in the real world. Annual Review of Psychology, 60, 549-576.

Henson, J.M., Reise, S.P., \& Kim, K.H. (2007). Detecting mixtures from structural model differences using latent variable mixture modeling: A comparison of relative model fit statistics. Structural Equation Modeling, 14, 202-226.

Hipp, J.R., \& Bauer, D.J. (2006). Local solutions in the estimation of growth mixture models. Psychological Methods, 11, 36-53. 
Hobfoll, S.E. (2002). Social and psychological resources and adaptation. Review of General Psychology, 6, 307-324.

Huyghebaert, T., Fouquereau, E., Lahiani, F.-J., Beltou, N., Gimenes, G., \& Gillet, N. (2018). Examining the longitudinal effects of workload on ill-being through each dimension of workaholism. International Journal of Stress Management, 25, 144-162.

Huyghebaert, T., Gillet, N., Fernet, C., Lahiani, F.-J., Chevalier, S., \& Fouquereau, E. (2018). Investigating the longitudinal effects of surface acting on managers' functioning through psychological needs. Journal of Occupational Health Psychology, 23, 207-222.

Iverson, R.D., \& Deery, S.J. (2001). Understanding the "personological" basis of employee withdrawal: The influence of affective disposition on employee tardiness, early departure, and absenteeism. Journal of Applied Psychology, 86, 856-866.

Jeličič, H., Phelps, E., \& Lerner, R.M. (2009). Missing data methods in longitudinal studies: The persistence of bad practices. Developmental Psychology, 45, 1195-1199.

Kam, C., Morin, A.J.S., Meyer, J.P., \& Topolnytsky, L. (2016). Are commitment profiles stable and predictable? A latent transition analysis. Journal of Management, 42, 1462-1490.

Kanat-Maymon, Y., Yaakobi, E., \& Roth, G. (2018). Motivating deference: Employees' perception of authority legitimacy as a mediator of supervisor motivating styles and employee work-related outcomes. European Management Journal, 36, 769-783.

Kessler, R.C., Barber, C., Beck, A., Berglund, P., Cleary, P.D., McKenas, D., \& Pronk, N. (2003). The world health organization health and work performance questionnaire (HPQ). Journal of Occupational and Environmental Medicine, 45, 156-174.

Kong, D.T., \& Ho, V.T. (2016). A self-determination perspective of strengths use at work: Examining its determinant and performance implications. The Journal of Positive Psychology, 11, 15-25.

Larsen, R. (2011). Missing data imputation versus full information maximum likelihood with second level dependencies. Structural Equation Modeling, 18, 649-662.

Lindebaum, D., \& Jordan, P.J. (2012). Positive emotions, negative emotions, or utility of discrete emotions? Journal of Organizational Behavior, 33, 1027-1030.

Liu, D., Chen, X.P., \& Yao, X. (2011). From autonomy to creativity: A multilevel investigation of the mediating role of harmonious passion. Journal of Applied Psychology, 96, 294-309.

Liu, D., Zhang, S., Wang, L., \& Lee, T.W. (2011). The effects of autonomy and empowerment on employee turnover: Test of a multilevel model in teams. Journal of Applied Psychology, 96, 13051316.

Lloyd, K.J., Boer, D., Keller, J.W., \& Voelpel, S. (2015). Is my boss really listening to me? The impact of perceived supervisor listening on emotional exhaustion, turnover intention, and organizational citizenship behavior. Journal of Business Ethics, 130, 509-524.

Lo, Y., Mendell, N., \& Rubin, D. (2001). Testing the number of components in a normal mixture. Biometrika, 88, 767-778.

Mäder, I..A., \& Niessen, C. (2017). Nonlinear associations between job insecurity and adaptive performance: The mediating role of negative affect and negative work reflection. Human Performance, 30, 231-253.

Mäkikangas, A., Hyvönen, K., \& Feldt, T. (2017). The energy and identification continua of burnout and work engagement: Developmental profiles over eight years. Burnout Research, 5, 44-54.

Mäkikangas, A., Hyvönen, K., Leskinen, E., Kinnunen, U., \& Feldt, T. (2011). A person-centred approach to investigate the development trajectories of job-related affective well-being: A 10-year follow-up study. Journal of Occupational and Organizational Psychology, 84, 327-346.

Mäkikangas, A., Kinnunen, S., Rantanen, J., Mauno, S., Tolvanen, A., \& Bakker, A.B. (2014). Association between vigor and exhaustion during the workweek: A person-centered approach to daily assessments. Anxiety, Stress \& Coping, 27, 555-575.

Mäkikangas, A., Schaufeli, W., Leskinen, E., Kinnunen, U., Hyvönen, K., \& Feldt, T. (2016). Longterm development of employee well-being: A latent transition approach. Journal of Happiness Studies, 17, 2325-2345.

Marsh, H.W., Lüdtke, O., Trautwein, U., \& Morin, A.J.S. (2009). Classical latent profile analysis of academic self-concept dimensions: Synergy of person- and variable-centered approaches to theoretical models of self-concept. Structural Equation Modeling, 16, 191-225. 
Martinent, G., \& Nicolas, M. (2016). A latent profile transition analysis of coping within competitive situations. Sport, Exercise, and Performance Psychology, 5, 218-231.

Martinent, G., \& Nicolas, M. (2017a). Athletes' affective profiles within competition situations: A two-wave study. Sport, Exercise, and Performance Psychology, 6, 143-157.

Martinent, G., \& Nicolas, M. (2017b). Temporal ordering of affective states and coping within a naturalistic achievement-related demanding situation. International Journal of Stress Management, 24, 29-51.

Martinent, G., Nicolas, M., Gaudreau, P., \& Campo, M. (2013). A cluster analysis of affective states before and during competition. Journal of Sport \& Exercise Psychology, 35, 600-611.

Mason, C.M., \& Griffin, M.A. (2003). Group absenteeism and positive affective tone: A longitudinal study. Journal of Organizational Behavior, 24, 667-687.

McLachlan, G., \& Peel, D. (2000). Finite mixture models. New York, NY: Wiley.

McNall, L.A., Tombari, J.M., \& Brown, M.M. (2019). Exploring how mindfulness links to work outcomes: Positive affectivity and work-life enrichment. Applied Research in Quality of Life. Advance online publication. https://doi.org.proxy/10.1007/s11482-019-09762-9

Meyer, J.P., \& Morin, A.J.S. (2016). A person-centered approach to commitment research: Theory, research, and methodology. Journal of Organizational Behavior, 37, 584-612.

Meyer, J.P., Morin, A.J.S., \& Wasti, S.A. (2018). Employee commitment before and after an economic crisis: A stringent test of profile similarity. Human Relations, 71, 1204-1233.

Millsap, R.E. (2011). Statistical approaches to measurement invariance. New York, NY: Taylor \& Francis.

Moreau, E., \& Mageau, G.A. (2012). The importance of perceived autonomy support for the psychological health and work satisfaction of health professionals: Not only supervisors count, colleagues too! Motivation and Emotion, 36, 268-286.

Morin, A.J.S. (2016). Person-centered research strategies in commitment research. In J.P. Meyer (Ed.), The handbook of employee commitment (pp. 490-508). Cheltenham, UK: Edward Elgar.

Morin, A.J.S., \& Litalien, D. (2017). Webnote: Longitudinal tests of profile similarity and latent transition analyses. Montreal, QC: Substantive Methodological Synergy Research Laboratory. http://smslabstats.weebly.com/uploads/1/0/0/6/100647486/lta_distributional_similarity_v02.pdf

Morin, A.J.S., \& Wang, J.C.K. (2016). A gentle introduction to mixture modeling using physical fitness data. In N. Ntoumanis \& N. Myers (Eds.), An introduction to intermediate and advanced statistical analyses for sport and exercise scientists (pp. 183-210). London, UK: Wiley.

Morin, A.J.S., Boudrias, J.-S., Marsh, H.W., Madore, I., \& Desrumaux, P. (2016). Further reflections on disentangling shape and level effects in person-centered analyses: An illustration aimed at exploring the dimensionality of psychological health. Structural Equation Modeling, 23, 438-454.

Morin, A.J.S., Boudrias, J.-S., Marsh, H.W., McInerney, D.M., Dagenais-Desmarais, V., Madore, I., \& Litalien, D. (2017). Complementary variable- and person-centered approaches to the dimensionality of psychometric constructs: Application to psychological wellbeing at work. Journal of Business and Psychology, 32, 395-419.

Morin, A.J.S., Maïano, C., Nagengast, B., Marsh, H.W., Morizot, J., \& Janosz, M. (2011). Growth mixture modeling of adolescents trajectories of anxiety: The impact of untested invariance assumptions on substantive interpretations. Structural Equation Modeling, 18, 613-648.

Morin, A.J.S., Meyer, J.P., Creusier, J., \& Biétry, F. (2016). Multiple-group analysis of similarity in latent profile solutions. Organizational Research Methods, 19, 231-254.

Morin, A.J.S., Morizot, J., Boudrias, J.-S., \& Madore, I. (2011). A multifoci person-centered perspective on workplace affective commitment: A latent profile/factor mixture analysis. Organizational Research Methods, 14, 58-90.

Morris, W.N., \& Reilly, N.P. (1987). Toward the self-regulation of mood: Theory and research. Motivation and Emotion, 11, 215-249.

Muthén, B.O. (2003). Statistical and substantive checking in growth mixture modeling: Comment on Bauer and Curran (2003). Psychological Methods, 8, 369-377.

Muthén, L.K., \& Muthén, B. (2017). Mplus user's guide. Los Angeles, CA: Muthén \& Muthén.

Nicolas, M., Martinent, G., \& Campo, M. (2014). Evaluation of the psychometric properties of a modified Positive and Negative Affect Schedule including a direction scale (PANAS-D) among French athletes. Psychology of Sport and Exercise, 15, 227-237. 
Nylund, K.L., Asparouhov, T., \& Muthén, B. (2007). Deciding on the number of classes in latent class analysis and growth mixture modeling: A Monte Carlo simulation study. Structural Equation Modeling, 14, 535-569.

Paulson, D., \& Leuty, M.E. (2016). Dispositional coping, personality traits, and affective style relating to conflict between work and family domains. Journal of Family and Economic Issues, 37, 519539.

Pekrun, R., Elliot, A.J., \& Maier, M.A. (2009). Achievement goals and achievement emotions: Testing a model of their joint relations with academic performance. Journal of Educational Psychology, 101, 115-135.

Peugh, J., \& Fan, X. (2013). Modeling unobserved heterogeneity using latent profile analysis: A Monte Carlo simulation. Structural Equation Modeling, 20, 616-639.

Porfeli, E.J., Lee, B., \& Weigold, I.K. (2012). A multidimensional measure of work valences. Journal of Vocational Behavior, 80, 340-350.

Raykov, T., \& Marcoulides, G.A. (2004). Using the delta method for approximate interval estimation of parameter functions in SEM. Structural Equation Modeling, 11, 621-637.

Reio, T.G., Jr., \& Ghosh, R. (2009). Antecedents and outcomes of workplace incivility: Implications for human resource development research and practice. Human Resource Development Quarterly, 20, 237-264.

Ryan, R.M., \& Deci, E.L. (2017). Self-determination theory: Basic psychological needs in motivation, development, and wellness. New York, NY: Guilford.

Sandrin, É, Gillet, N., Fernet, C., Depin-Rouault, C., Leloup, M., \& Portenard, D. (2019). Effects of workaholism on volunteer firefighters' performance: A moderated mediation model including supervisor recognition and emotional exhaustion. Anxiety, Stress, \& Coping, 32, 568-580.

Sandrin, É., Gillet, N., Fernet, C., Leloup, M., \& Depin- Rouault, C. (2019). Effects of motivation and workload on firefighters' perceived health, stress, and performance. Stress and Health, 35, 447456.

Sapolsky, R.M. (1999). The physiology and pathophysiology of unhappiness. In D. Kahneman, E. Diener, \& N. Schwarz (Eds.), Well-being: The foundations of hedonic psychology (pp. 453-469). New York, NY: The Russell Sage Foundation.

Scheibe, S., Yeung, D.Y., \& Doerwald, F. (2019). Age-related differences in levels and dynamics of workplace affect. Psychology and Aging, 34, 106-123.

Skrondal, A., \& Laake, P. (2001). Regression among factor scores. Psychometrika, 66, 563-576.

Slemp, G.R., Kern, M.L., Patrick, K.J., \& Ryan, R.M. (2018). Leader autonomy support in the workplace: A meta-analytic review. Motivation and Emotion, 42, 706-724.

Tein, J.-Y., Coxe, S., \& Cham, H. (2013). Statistical power to detect the correct number of classes in latent profile analysis. Structural Equation Modeling, 20, 640-657.

Tement, S., \& Korunka, C. (2013). Does trait affectivity predict work-to-family conflict and enrichment beyond job characteristics? The Journal of Psychology: Interdisciplinary and Applied, 147, 197-216.

Tóth-Király, I., Bőthe, B., Orosz, G., \& Rigó, A. (2019). On the importance of balanced need fulfillment: A person-centered perspective. Journal of Happiness Studies. Advance online publication. doi: 10.1007/s10902-018-0066-0

Vandercammen, L., Hofmans, J., \& Theuns, P. (2014). The mediating role of affect in the relationship between need satisfaction and autonomous motivation. Journal of Occupational and Organizational Psychology, 87, 62-79.

Watson, D., Clark, L.A., \& Tellegen, A. (1988). Development and validation of brief measures of positive and negative affect: The PANAS scales. Journal of Personality and Social Psychology, 54, 1063-1070.

Weiss, H.M., \& Cropanzano, R. (1996). Affective events theory: A theoretical discussion of the structure, causes and consequences of affective experiences at work. In B.M. Staw \& L.L. Cummings (Eds.), Research in organizational behavior: An annual series of analytical essays and critical reviews, Vol. 18 (pp. 1-74). Stamford, CT: JAI Press.

Zhao, J.-L., Li, X.-H., \& Shields, J. (2019). Managing job burnout: The effects of emotion-regulation ability, emotional labor, and positive and negative affect at work. International Journal of Stress Management, 26, 315-320. 
Zyphur, M.J. (2009). When mindsets collide: Switching analytical mindsets to advance organization science. The Academy of Management Review, 34, 677-688.

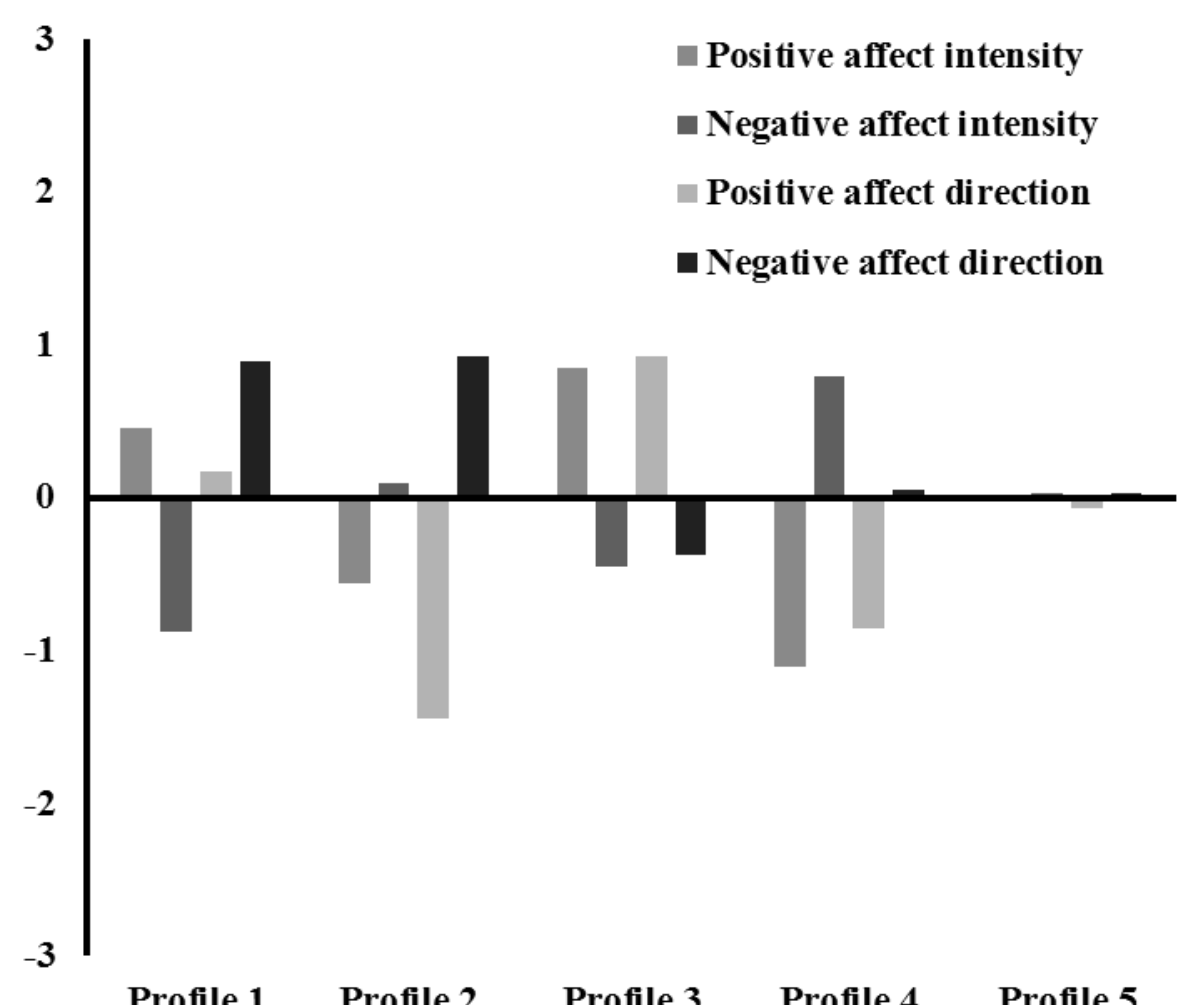

Figure 1. Final five-profile solution found in this study at both time points.

Note. Profile indicators are estimated from factor scores with a mean of 0 and a standard deviation of 1; Profile 1: Low Negative Affect Facilitators; Profile 2: Moderately Low Positive Affect Incapacitators; Profile 3: High Positive Affect Facilitators; Profile 4: Very Low Positive Affect Incapacitators; Profile 5: Normative. 


\section{Table 1}

Time-Specific Latent Profile Analyses

\begin{tabular}{|c|c|c|c|c|c|c|c|c|c|c|}
\hline Model & LL & $\# \mathrm{fp}$ & Scaling & AIC & CAIC & BIC & $\mathrm{ABIC}$ & Entropy & aLMR & BLRT \\
\hline 2 Profiles & -2463.395 & 17 & 1.118 & 4960.791 & 5049.130 & 5032.130 & 4978.172 & .919 & $<.001$ & $<.001$ \\
\hline 3 Profiles & -2350.914 & 26 & 1.251 & 4753.828 & 4888.935 & 4862.935 & 4780.412 & .793 & .002 & $<.001$ \\
\hline 5 Profiles & -2226.015 & 44 & 1.127 & 4540.029 & 4766.673 & 4724.673 & 4585.017 & .842 & $<.001$ & $<.001$ \\
\hline 6 Profiles & -2184.887 & 53 & 1.188 & 4475.774 & 4751.185 & 4698.185 & 4529.964 & .797 & .238 & $<.001$ \\
\hline 7 Profiles & -2142.510 & 62 & 1.258 & 4409.020 & 4731.200 & 4669.200 & 4472.412 & .825 & .511 & $<.001$ \\
\hline 1 Profile & -2094.971 & 8 & 1.351 & 4205.943 & 4247.514 & 4239.514 & 4214.123 & $\mathrm{Na}$ & $\mathrm{Na}$ & $\mathrm{Na}$ \\
\hline 2 Profiles & -1948.778 & 17 & 1.966 & 3931.556 & 4019.896 & 4002.896 & 3948.938 & .624 & .120 & $<.001$ \\
\hline 3 Profiles & -1816.688 & 26 & 1.549 & 3685.376 & 3820.484 & 3794.484 & 3711.960 & .745 & .031 & $<.001$ \\
\hline 4 Profiles & -1760.768 & 35 & 1.543 & 3591.536 & 3773.411 & 3738.411 & 3627.322 & .761 & .438 & $<.001$ \\
\hline 5 Profiles & -1716.897 & 44 & 1.410 & 3521.793 & 3750.437 & 3706.437 & 3566.781 & .759 & .241 & $<.001$ \\
\hline 6 Profiles & -1683.834 & 53 & 1.340 & 3473.667 & 3749.079 & 3696.079 & 3527.857 & .784 & .302 & $<.001$ \\
\hline 7 Profiles & -1652.602 & 62 & 1.260 & 3429.203 & 3751.383 & 3689.383 & 3492.595 & .805 & .329 & $<.001$ \\
\hline
\end{tabular}

Note. LL: model loglikelihood; \#fp: number of free parameters; scaling: scaling correction factor associated with robust maximum likelihood estimates; AIC: Akaïke information criteria; CAIC: constant AIC; BIC: Bayesian information criteria; ABIC: sample size adjusted BIC; aLMR: adjusted Lo-Mendel-Rubin likelihood ratio test; BLRT: bootstrap likelihood ratio test. 
Table 2

Longitudinal Latent Profile and Latent Transition Analyses

\begin{tabular}{|c|c|c|c|c|c|c|c|c|}
\hline Model & LL & $\mathrm{fp}$ & Sc & AIC & CAIC & BIC & $\mathrm{ABIC}$ & Entropy \\
\hline \multicolumn{9}{|l|}{ Final Time-Specific Models } \\
\hline Time 1 & -2226.015 & 44 & 1.127 & 4540.029 & 4766.673 & 4724.673 & 4585.017 & .842 \\
\hline Time 2 & -1716.897 & 44 & 1.410 & 3521.793 & 3750.437 & 3706.437 & 3566.781 & .759 \\
\hline \multicolumn{9}{|l|}{ Longitudinal Tests of Similarity } \\
\hline Configural & -3942.911 & 88 & 1.269 & 8061.822 & 8519.110 & 8431.110 & 8151.799 & .801 \\
\hline Structural & -3993.499 & 68 & 1.502 & 8122.998 & 8476.356 & 8408.356 & 8192.525 & .813 \\
\hline Dispersion & -4088.802 & 48 & 1.627 & 8273.605 & 8523.034 & 8475.034 & 8322.683 & .752 \\
\hline Partial Dispersion & -4040.024 & 52 & 1.472 & 8184.048 & 8454.263 & 8402.263 & 8237.215 & .828 \\
\hline Distributional & -4060.852 & 48 & 1.528 & 8217.704 & 8467.134 & 8419.134 & 8266.782 & .829 \\
\hline Latent Transition Analysis & -3776.762 & 24 & .625 & 7601.524 & 7726.238 & 7702.238 & 7626.063 & 931 \\
\hline \multicolumn{9}{|l|}{ Demographics } \\
\hline Null Effects Model & -6320.530 & 33 & .716 & 12707.060 & 12878.543 & 12845.543 & 12740.801 & .931 \\
\hline Profile-Specific Free Relations with Predictors & -6281.394 & 117 & .408 & 12796.788 & 13404.772 & 13287.772 & 12916.416 & .940 \\
\hline Free Relations with Predictors & -6303.207 & 57 & .882 & 12720.414 & 13016.611 & 12959.611 & 12778.694 & .937 \\
\hline Predictive Similarity & -6310.240 & 45 & .782 & 12710.480 & 12944.320 & 12899.320 & 12756.490 & .932 \\
\hline \multicolumn{9}{|l|}{ Predictors } \\
\hline Null Effects Model & -5157.259 & 38 & .814 & 10390.517 & 10587.982 & 10549.982 & 10429.371 & .931 \\
\hline Profile-Specific Free Relations with Predictors & -5066.553 & 62 & 1.002 & 10257.105 & 10579.285 & 10517.285 & 10320.497 & .936 \\
\hline Free Relations with Predictors & -5070.180 & 54 & .969 & 10248.361 & 10528.968 & 10474.968 & 10303.573 & .935 \\
\hline Predictive Similarity & -5079.729 & 46 & .857 & 10251.458 & 10490.495 & 10444.495 & 10298.491 & .931 \\
\hline \multicolumn{9}{|l|}{ Outcomes } \\
\hline Free Relations with Outcomes & -7382.318 & 54 & 1.620 & 14872.635 & 15153.243 & 15099.243 & 14927.848 & .937 \\
\hline Explanatory Similarity & -7387.498 & 44 & 1.828 & 14862.995 & 15091.639 & 15047.639 & 14907.983 & .935 \\
\hline
\end{tabular}

Note. LL: loglikelihood; fp: free parameters; Sc: correction factor for robust maximum likelihood estimation; AIC: Akaïke information criteria; BIC: Bayesian information criteria; CAIC: constant AIC; ABIC: sample size adjusted BIC; BLRT: bootstrap likelihood ratio test; aLMR: adjusted Lo-Mendel-Rubin likelihood ratio test. 
Table 3

Transitions Probabilities

\begin{tabular}{|c|c|c|c|c|c|c|c|}
\hline & Profile 1 & Profile 2 & Profile 3 & Profile 4 & Profile 5 & Profile Size Time 1 & Profile Size Time 2 \\
\hline \multicolumn{8}{|l|}{ Time 1} \\
\hline Profile 1 & .093 & .045 & .190 & .000 & .672 & $9.83 \%$ & $1.54 \%$ \\
\hline Profile 2 & .000 & .035 & .000 & .760 & .205 & $5.56 \%$ & $1.87 \%$ \\
\hline Profile 3 & .000 & .000 & .989 & .011 & .000 & $22.48 \%$ & $21.36 \%$ \\
\hline Profile 4 & .000 & .017 & .000 & .983 & .000 & $18.41 \%$ & $17.23 \%$ \\
\hline Profile 5 & .011 & .019 & .009 & .003 & .958 & $43.73 \%$ & $58.00 \%$ \\
\hline
\end{tabular}

Note. Profile 1: Low Negative Affect Facilitators; Profile 2: Moderately Low Positive Affect Incapacitators; Profile 3: High Positive Affect Facilitators; Profile 4: Very Low Positive Affect Incapacitators; Profile 5: Normative. 


\section{Table 4}

Relations between the Predictors and Profile Membership (Predictive Similarity)

\begin{tabular}{|c|c|c|c|c|c|c|c|c|c|c|}
\hline & \multicolumn{2}{|c|}{ Profile 1 vs. Profile 5} & \multicolumn{2}{|c|}{ Profile 2 vs. Profile 5} & \multicolumn{2}{|c|}{ Profile 3 vs. Profile 5} & \multicolumn{2}{|c|}{ Profile 4 vs. Profile 5} & \multicolumn{2}{|c|}{ Profile 1 vs. Profile 4} \\
\hline & Coef. (SE) & OR & Coef. (SE) & OR & Coef. (SE) & OR & Coef. (SE) & OR & Coef. (SE) & OR \\
\hline Global Need & $.841(.284)^{* *}$ & 2.318 & $-.691(.337)^{*}$ & .501 & $.938(.237)^{* *}$ & 2.556 & $-1.910(.327)^{* *}$ & .148 & $2.751(.407)^{* *}$ & 15.659 \\
\hline \multirow[t]{3}{*}{ Aut. Support } & $-.286(.287)$ & .751 & $-.112(.279)$ & .894 & $-.114(.210)$ & .892 & $.356(.238)$ & 1.428 & $-.642(.340)$ & .526 \\
\hline & \multicolumn{2}{|c|}{ Profile 2 vs. Profile 4} & \multicolumn{2}{|c|}{ Profile 3 vs. Profile 4} & \multicolumn{2}{|c|}{ Profile 1 vs. Profile 3} & \multicolumn{2}{|c|}{ Profile 2 vs. Profile 3} & \multicolumn{2}{|c|}{ Profile 1 vs. Profile 2} \\
\hline & Coef. (SE) & OR & Coef. (SE) & OR & Coef. (SE) & OR & Coef. (SE) & OR & Coef. (SE) & OR \\
\hline Global Need & $1.219(.450)^{* *}$ & 3.383 & $2.849(.393)^{* *}$ & 17.264 & $-.098(.315)$ & .907 & $-1.630(.415)^{* *}$ & .196 & $1.532(.441)^{* *}$ & 4.629 \\
\hline Aut. Support & $-.468(.334)$ & .626 & $-.470(.283)$ & .625 & $-.172(.308)$ & .842 & $.002(.321)$ & 1.002 & $-.174(.375)$ & .840 \\
\hline
\end{tabular}

Note. ${ }^{*} p<.05 ; *^{*} p<.01$; SE: standard error of the coefficient; OR: odds ratio; Global Need: global levels of need satisfaction; Aut. Support: autonomy support; the predictors are factor scores with a standard deviation of 1 and a mean of 0 ; the coefficients and OR reflect the effects of the predictors on the likelihood of membership into the first listed profile relative to the second listed profile; Profile 1: Low Negative Affect Facilitators; Profile 2: Moderately Low Positive Affect Incapacitators; Profile 3: High Positive Affect Facilitators; Profile 4: Very Low Positive Affect Incapacitators; Profile 5: Normative. 


\section{Table 5}

Relations between Profile Membership and the Outcomes (Explanatory Similarity)

\begin{tabular}{|c|c|c|c|c|c|c|}
\hline & $\begin{array}{l}\text { Profile } 1 \\
\mathrm{M}[\mathrm{CI}]\end{array}$ & $\begin{array}{l}\text { Profile } 2 \\
\mathrm{M}[\mathrm{CI}]\end{array}$ & $\begin{array}{l}\text { Profile } 3 \\
\mathrm{M}[\mathrm{CI}]\end{array}$ & $\begin{array}{c}\text { Profile } 4 \\
\mathrm{M}[\mathrm{CI}]\end{array}$ & $\begin{array}{l}\text { Profile } 5 \\
\mathrm{M}[\mathrm{CI}]\end{array}$ & $\begin{array}{c}\text { Summary of Significant } \\
\text { Differences }\end{array}$ \\
\hline Turnover Intentions* & $-.351[-.575 ;-.127]$ & $.295[.052 ; .538]$ & $-.318[-.478 ;-.157]$ & $.779[.64 ; .917]$ & $.012[-.105 ; .129]$ & $4>2>5>1=3$ \\
\hline $\begin{array}{l}\text { Work-Family } \\
\text { Conflict* }\end{array}$ & $-.150[-.502 ; .202]$ & $-.031[-.311 ; .249]$ & $-.241[-.460 ;-.023]$ & $.264[.059 ; .47]$ & $.047[-.079 ; .172]$ & $\begin{array}{c}4>1=3 ; 5>3 ; 2=4 \\
1=2=3 ; 1=2=5\end{array}$ \\
\hline Absenteeism & $.214[-.358 ; .786]$ & $.682[-.395 ; 1.759]$ & $2.510[1.114 ; 3.907]$ & $6.337[2.81 ; 9.864]$ & $5.683[1.407 ; 9.958]$ & $\begin{array}{c}4=5>2>1 ; \\
4>3>2>1 ; 3=5\end{array}$ \\
\hline
\end{tabular}

Note. M: mean; CI: 95\% confidence interval; * factor scores with a standard deviation of 1 and a mean of 0; Profile 1: Low Negative Affect Facilitators;

Profile 2: Moderately Low Positive Affect Incapacitators; Profile 3: High Positive Affect Facilitators; Profile 4: Very Low Positive Affect Incapacitators; Profile 5: Normative. 


\section{Online Supplemental Materials for:}

\section{A Longitudinal Person-Centered Perspective on Positive and Negative Affect at Work}

\section{Authors' note:}

These online technical appendices are to be posted on the journal website and hot-linked to the manuscript. If the journal does not offer this possibility, these materials can alternatively be posted on one of our personal websites (we will adjust the in-text reference upon acceptance).

We would also be happy to have some of these materials brought back into the main manuscript, or included as published appendices if you deem it useful. We developed these materials to provide additional technical information and to keep the main manuscript from becoming needlessly long. 


\section{Preliminary Measurement Models \\ Analyses: Model Estimation and Specification}

Preliminary analyses were realized using Mplus 8 (Muthén \& Muthén, 2017) mean and variance adjusted weight least square estimator (WLSMV) to account for the ordered-categorical Likert ratings used in this research (Finney \& DiStefano, 2013). All available information was used in model estimation. Item-level missing data remained low (i.e., 0 to $9.0 \%$ at Time $1 ; 0$ to $4.7 \%$ at Time 2). The complexity of these longitudinal measurement models made it necessary to conduct the analyses distinctly for the affect measure, for the multi-items predictors (need satisfaction and autonomy support), and for the multiitem outcomes (turnover intentions and work-family conflict). For the affect measure, a confirmatory factor analytic (CFA) model including four correlated first-order factors (positive affect intensity and direction; negative affect intensity and direction) was estimated at each time point. To ascertain the empirically distinct nature of each of the affect components considered in this model, we contrasted the a priori four-factor measurement model with six three-factor models in which the affect components were combined in a pairwise manner, two two-factor models (combining pairs of factors based on the valence of the affect, or on the intensity/direction distinction) and one one-factor model.

For the predictors and outcomes, a model including three correlated CFA factors (work-family conflict, perceived autonomy support, and turnover intentions) and a bifactor-CFA (e.g., Holzinger \& Swineford, 1937; Morin, Arens, \& Marsh, 2016) specification of participants' need satisfaction was estimated at each time point. The bifactor-CFA component included a global factor (G-factor) reflecting participants' levels of need satisfaction across all three needs, and three orthogonal factors (S-factors) reflecting specific levels of relatedness, autonomy, and competence needs satisfaction left unexplained by this global level. The decision to rely on this bifactor-CFA model is aligned with recent psychometric research evidence supporting the superiority of this operationalization of need satisfaction ratings in the educational (Garn, Morin, \& Lonsdale, 2018; Gillet et al., 2018), sport (Brunet, Gunnell, Teixeira, Sabiston, \& Bélanger, 2016), work (Bidee, Vantilborgh, Pepermans, Griep, \& Hofmans, 2016; Sánchez-Oliva et al., 2017), and general life (Tóth-Király, Morin, Bőthe, Orosz, \& Rigó, 2018) domains. These studies all demonstrated that this approach made it possible to obtain a direct estimate of participants' global levels of need satisfaction (G-factor), while taking into account the specificity associated with each need (S-factors). Yet, this previous research also showed that the G-factor (global levels of need satisfaction) is typically the key component of this model in the context of predictive analyses, and that this bifactor approach often results in "vanishing" S-factors. For this reason, coupled with the complexity of our main analytic models (suggesting the need to parsimony) and the fact that our research objectives only focused on global need satisfaction effects, only the G-factor was retained for our main analyses.

Longitudinal models were directly estimated across the two time waves and incorporated eight correlated factors (i.e., 4 factors $\mathrm{x} 2$ times) for the affect measure and 14 correlated factors (with the exception of the bifactor components specified to be orthogonal with one another) for the predictors and outcomes (i.e., ([1 G-factor $+3 \mathrm{~S}$-factors $]+3$ factors) $\mathrm{x} 2$ times). Correlated uniquenesses were specified a priori between matching items of the factors used across time waves to avoid converging on inflated estimates of longitudinal stability (e.g., Marsh, 2007). The measurement invariance of these models was systematically tested over time according to the following sequence (Millsap, 2011): (i) configural (same model); (ii) weak (same loadings); (iii) strong (same intercepts); (iv) strict (same uniquenesses); (v) latent variances and covariances (same latent variance-covariance matrix); and (vi) latent means (same latent means).

Model fit was assessed on the basis of sample-size independent fit indices to account for the oversensitivity (to sample size and minor misspecifications) of the chi-square $\left(\chi^{2}\right)$ and of chi-square difference tests (e.g., Hu \& Bentler, 1999; Marsh, Hau, \& Grayson, 2005). More precisely, we considered values over than .90 on the comparative fit index (CFI) and on the Tucker-Lewis index (TLI) to support adequate fit, and values over 95 to support excellent fit. For the root mean square error of approximation (RMSEA), matching values were respectively smaller than .08 and .06 . For tests of invariance, we considered changes $(\Delta)$ in CFI/TLI of .010 or less and $\triangle$ RMSEA of .015 or less to support the most invariant model in the comparison.

\section{Results: Preliminary Measurement Models}

The fit results from all solutions are presented in Table S1, and support the adequacy of the models underlying the affect measures (with all CFI/TLI $\geq .95$, and RMSEA $\leq .08$ ) and of the predictor and 
outcome measures (with all CFI/TLI $\geq .95$ and RMSEA $\leq .08$ ). Tests of measurement invariance also supported the complete invariance of both models over time $(\triangle \mathrm{RMSEA} \leq .015 ; \Delta \mathrm{CFI} / \mathrm{TLI} \leq .010)$. Finally, test of the discriminant validity of the affect factors, reported in Table S2, support the distinct nature of the affect components, supporting the superiority of the a priori measurement model in terms of model fit relative to that of the other solutions $(\Delta \mathrm{CFI} \geq .014, \mathrm{TLI} \geq .016$, and $\triangle \mathrm{RMSEA} \geq .013)$.

The detailed results from the affect models appear in Table S3. With the exception of a single item which did not perform as well as the others (item 4 from the positive affect direction subscale with a $\lambda$ $=.217$ at Time $1, .157$ at Time 2, and .205 for the invariant model), the results revealed that all firstorder factors are well-defined at both time points by the other items $(\lambda=.424$ to .960 at Time $1 ; \lambda=$ .403 to .958 at Time $2 ; \lambda=.406$ to .966 for the invariant model), and resulted in satisfactory estimates of composite reliability ( $\omega=.881$ to .976 ; McDonald, 1970).

The results also support the adequacy of the CFA and B-CFA models underlying the predictors and outcomes (see Table S4). First, they revealed a reasonably well-defined need satisfaction G-factor $(\lambda=$ .418 to .834$)$ at both time points, as well as well-defined autonomy $(\lambda=.182$ to .618$)$ and relatedness $(\lambda=.226$ to .610) S-factors. Likewise, these results showed that only a negligible level of specificity remains associated with the competence $\mathrm{S}$-factor, an observation that was fully replicated across time points (Time $1: \lambda=-.196$ to .619 ; Time $2: \lambda=-.125$ to $.633 ; \lambda=-.051$ to .558 for the invariant model). Second, the results revealed well-defined autonomy support $(\lambda=.805$ to .920 at Time $1 ; \lambda=.775$ to .945 at Time $2 ; \lambda=.801$ to .922 for the invariant model), work-family conflict ( $\lambda=.882$ to .932 at Time $1 ; \lambda=.915$ to .975 at Time $2 ; \lambda=.894$ to .951 for the invariant model), and turnover intentions ( $\lambda=.661$ to .963 at Time $1 ; \lambda=.734$ to .988 at Time $2 ; \lambda=.683$ to .954 for the invariant model) factors over time. All factors used in the analyses reported in the main article resulted in satisfactory estimates of composite reliability (McDonald, 1970): $\omega=.935$ to .943 for global levels of need satisfaction, $\omega=.960$ to .968 for autonomy support, $\omega=.931$ to .956 for work-family conflict, and $\omega=$ .892 to .906 for turnover intentions.

To ensure that the time-specific measures could be considered to be fully comparable across time points, factor scores were saved from the model of latent mean invariance. Saving factor scores from this model allowed us to obtain easy to compared time-specific construct estimates expressed in standardized units $(M=0 ; S D=1)$. Pairwise correlations observed for all variables used in the main analyses appear in Table S5, and support the distinctiveness of all constructs considered here.

\section{References used in this supplement}

Bidee, J., Vantilborgh, T., Pepermans, R., Griep, Y., \& Hofmans, J. (2016). Temporal dynamics of need satisfaction and need frustration. Two sides of the same coin? European Journal of Work and Organizational Psychology, 25, 900-913.

Brunet, J., Gunnell, K., Teixeira, P.J., Sabiston, C., \& Bélanger, M. (2016). Should we be looking at the forest or the trees? Overall psychological need satisfaction and individual needs as predictors of physical activity. Journal of Sport \& Exercise Psychology, 38, 317-330.

Chen, F.F. (2007). Sensitivity of goodness of fit indexes to lack of measurement. Structural Equation Modeling, 14, 464-504.

Cheung, G.W., \& Rensvold, R.B. (2002). Evaluating goodness-of-fit indexes for testing measurement invariance. Structural Equation Modeling, 9, 233-255.

Finney, S.J., \& DiStefano, C. (2013). Non-normal and categorical data in structural equation modeling. In G.R. Hancock \& R.O. Mueller (Eds), Structural equation modeling: A second course $\left(2^{\text {nd }}\right.$ ed., pp. 439-492). Greenwich, CO: IAP.

Garn, A.C., Morin, A.J.S., \& Lonsdale, C. (2018). Basic psychological need satisfaction toward learning: A longitudinal test of mediation using bifactor exploratory structural equation modeling. Journal of Educational Psychology. Advance online publication. doi: 10.1037/edu0000283

Gillet, N., Morin, A.J.S., Huyghebaert, T., Burger, L., Maillot, A., Poulin, A., \& Tricard, E. (2018). University students' need satisfaction trajectories: A growth mixture analysis. Learning \& Instruction. Advance online publication. doi: 10.1016/j.learninstruc.2017.11.003

Holzinger, K.J., \& Swineford, F. (1937). The bi-factor model. Psychometrika, 2, 1-17.

Hu, L., \& Bentler, P.M. (1999). Cutoff criteria for fit indexes in covariance structure analysis: Conventional criteria versus new alternatives. Structural Equation Modeling, 6, 1-55.

Marsh, H.W. (2007). Application of confirmatory factor analysis and structural equation modeling in 
sport/exercise psychology. In G. Tenenbaum \& R.C. Eklund (Eds.), Handbook of sport psychology ( $3^{\text {rd }}$ ed., pp. 774-798). Hoboken, NJ: Wiley.

Marsh, H.W., Hau, K.-T., \& Grayson, D. (2005). Goodness of fit evaluation in structural equation modeling. In A. Maydeu-Olivares \& J. McArdle (Eds.), Contemporary Psychometric (pp. 275340). Mahwah, NJ: Erlbaum.

McDonald, R. (1970). Theoretical foundations of principal factor analysis, canonical factor analysis, and alpha factor analysis. British Journal of Mathematical \& Statistical Psychology, 23, 1-21.

Millsap, R.E. (2011). Statistical approaches to measurement invariance. New York, NY: Taylor \& Francis.

Morin, A.J.S., Arens, A.K., \& Marsh, H. (2016). A bifactor exploratory structural equation modeling framework for the identification of distinct sources of construct-relevant psychometric multidimensionality. Structural Equation Modeling, 23, 116-139.

Muthén, L.K., \& Muthén, B. (2017). Mplus user's guide. Los Angeles, CA: Muthén \& Muthén.

Sánchez-Oliva, D., Morin, A.J.S., Teixeira, P.J., Carraça, E.V., Palmeira, A.L., \& Silva, M.N. (2017). A bifactor exploratory structural equation modeling representation of the structure of the Basic Psychological Needs at Work Scale. Journal of Vocational Behavior, 98, 173-187.

Tóth-Király, I., Morin, A.J.S., Bőthe, B., Orosz, G., \& Rigó, A. (2018). Investigating the multidimensionality of need fulfillment: A bifactor exploratory structural equation modeling representation. Structural Equation Modeling, 25, 267-286. 


\section{Table S1}

Preliminary Measurement Models: Fit Statistics

\begin{tabular}{|c|c|c|c|c|c|c|c|c|c|}
\hline Description & $\chi^{2}(d f)$ & CFI & TLI & RMSEA & $90 \% \mathrm{CI}$ & $\Delta \chi^{2}(d f)$ & $\Delta \mathrm{CFI}$ & $\Delta \mathrm{TLI}$ & $\Delta$ RMSEA \\
\hline \multicolumn{10}{|l|}{$\overline{A f f e c t}$} \\
\hline Time 1 & $2509.109(714)^{*}$ & .962 & .958 & .072 & {$[.069 ; .075]$} & & & & \\
\hline Time 2 & $1232.327(714) *$ & .961 & .958 & .074 & {$[.067 ; .081]$} & & & & \\
\hline Longitudinal: Configural invariance & $4425.520(2972) *$ & .965 & .962 & .032 & {$[.030 ; .033]$} & - & - & - & - \\
\hline Longitudinal: Weak invariance & $4457.116(3008)^{*}$ & .965 & .963 & .031 & {$[.029 ; .033]$} & $28.385(36)$ & .000 & +.001 & -.001 \\
\hline Longitudinal: Strong invariance & $4559.113(3148) *$ & .966 & .966 & .030 & {$[.028 ; .032]$} & $124.866(140)$ & +.001 & +.003 & -.001 \\
\hline Longitudinal: Strict invariance & $4577.120(3188) *$ & .966 & .967 & .030 & {$[.028 ; .032]$} & $77.794(40)^{*}$ & .000 & +.001 & .000 \\
\hline Longitudinal: Variance-Covariance invariance & $4436.214(3218)^{*}$ & .970 & .971 & .028 & {$[.026 ; .030]$} & $35.354(30)$ & +.004 & +.004 & -.002 \\
\hline Longitudinal: Latent means invariance & $4418.233(3222)^{*}$ & .971 & .971 & .027 & {$[.025 ; .029]$} & $3.277(4)$ & +.001 & .000 & -.001 \\
\hline \multicolumn{10}{|l|}{ Predictors and Outcomes } \\
\hline Time 1 & $1379.164(375)^{*}$ & .964 & .958 & .074 & {$[.070 ; .078]$} & & & & \\
\hline Time 2 & $576.967(375)^{*}$ & .976 & .973 & .062 & {$[.052 ; .072]$} & & & & \\
\hline Longitudinal: Configural invariance & $2301.896(1571)^{*}$ & .973 & .969 & .031 & {$[.028 ; .033]$} & - & - & - & - \\
\hline Longitudinal: Weak invariance & $2348.139(1609) *$ & .973 & .970 & .031 & {$[.028 ; .033]$} & $93.534(38) *$ & .000 & +.001 & .000 \\
\hline Longitudinal: Strong invariance & $2446.239(1735)^{*}$ & .974 & .973 & .029 & {$[.026 ; .032]$} & $131.196(126)$ & +.001 & +.003 & -.002 \\
\hline Longitudinal: Strict invariance & $2441.868(1765)^{*}$ & .975 & .975 & .028 & {$[.025 ; .031]$} & $42.322(30)$ & +.001 & +.002 & -.001 \\
\hline Longitudinal: Variance-Covariance invariance & $2368.260(1787)^{*}$ & .978 & .979 & .026 & {$[.023 ; .028]$} & $32.894(22)$ & +.003 & +.004 & -.002 \\
\hline Longitudinal: Latent means invariance & $2366.036(1794) *$ & .979 & .979 & .025 & {$[.023 ; .028]$} & $10.597(7)$ & +.001 & .000 & -.001 \\
\hline
\end{tabular}

Note. ${ }^{*} p<.05 ; \chi^{2}$ : scaled chi-square test of exact fit; $d f$ : degrees of freedom; CFI: comparative fit index; TLI: Tucker-Lewis index; RMSEA: root mean square error of approximation; $90 \%$ CI: $90 \%$ confidence interval; Var-Cov: variance-covariance; $\Delta$ : change in fit information relative to the previous model. 
Table S2

Preliminary Measurement Models: Discriminant Validity of the Affect Components

\begin{tabular}{lccccc}
\hline \multicolumn{1}{c}{ Description } & $\chi^{2}(d f)$ & CFI & TLI & RMSEA & $90 \%$ CI \\
\hline Time 1: 4 factors (PAI, NAI, PAD, NAD) & $2509.109(714)^{*}$ & .962 & .958 & .072 & {$[.069 ; .075]$} \\
Time 1: 3 factors (I, PAD, NAD) & $3939.794(717)^{*}$ & .931 & .925 & .096 & {$[.093 ; .099]$} \\
Time 1: 3 factors (PA, NAI, NAD) & $3212.157(717)^{*}$ & .947 & .942 & .085 & {$[.082 ; .088]$} \\
Time 1: 3 factors (PAI/NAD, NAI, PAD) & $6487.270(717)^{*}$ & .876 & .866 & .129 & {$[.126 ; .131]$} \\
Time 1: 3 factors (PAI, NAI/PAD, NAD) & $4320.746(717)^{*}$ & .923 & .916 & .102 & {$[.099 ; .105]$} \\
Time 1: 3 factors (PAI, NA, PAD) & $5149.512(717)^{*}$ & .905 & .897 & .113 & {$[.110 ; .116]$} \\
Time 1: 3 factors (PAI, NAI, D) & $14725.623(717)^{*} .700$ & .674 & .200 & {$[.197 ; .203]$} \\
Time 1: 2 factors (PA, NA) & $5621.438(719)^{*} .895$ & .886 & .118 & {$[.115 ; .121]$} \\
Time 1: 2 factors (I, D) & $15380.240(719)^{*} .686$ & .659 & .205 & {$[.202 ; .207]$} \\
Time 1: factor & $18989.053(720)^{*} .609$ & .576 & .228 & {$[.225 ; .231]$} \\
\hline Time 2: 4 factors (PAI, NAI, PAD, NAD) & $1232.327(714)^{*}$ & .961 & .958 & .074 & {$[.067 ; .081]$} \\
Time 2: 3 factors (I, PAD, NAD) & $1702.622(717)^{*}$ & .926 & .920 & .102 & {$[.096 ; .109]$} \\
Time 2: 3 factors (PA, NAI, NAD) & $1430.286(717)^{*}$ & .947 & .942 & .087 & {$[.081 ; .094]$} \\
Time 2: 3 factors (PAI/NAD, NAI, PAD) & $2360.950(717)^{*}$ & .877 & .866 & .132 & {$[.126 ; .138]$} \\
Time 2: 3 factors (PAI, NAI/PAD, NAD) & $1743.949(717)^{*}$ & .923 & .916 & .105 & {$[.098 ; .111]$} \\
Time 2: 3 factors (PAI, NA, PAD) & $2030.121(717)^{*}$ & .902 & .893 & .118 & {$[.112 ; .124]$} \\
Time 2: 3 factors (PAI, NAI, D) & $5284.031(717)^{*}$ & .657 & .627 & .221 & {$[.215 ; .226]$} \\
Time 2: 2 factors (PA, NA) & $2151.132(719)^{*} .893$ & .883 & .123 & {$[.127 ; .129]$} \\
Time 2: 2 factors (I, D) & $5524.739(719)^{*}$ & .640 & .609 & .226 & {$[.220 ; .231]$} \\
Time 2: factor & $6305.784(720)^{*} .581$ & .546 & .243 & {$[.238 ; .249]$} \\
\hline
\end{tabular}

Note. $* p<.05 ; \chi^{2}$ : Scaled chi-square test of exact fit; $d f$ : Degrees of freedom; CFI: Comparative fit index; TLI: Tucker-Lewis index; RMSEA: Root mean square error of approximation; $90 \%$ CI: $90 \%$ confidence interval; PAI: Positive affect intensity; NAI: Negative affect intensity; PAD: Positive affect direction; NAD: Negative affect direction; I: Intensity; D: Direction. 
Table S3

Standardized Factor Loadings ( $\lambda$ ) and Uniquenesses $(\delta)$ for the Affect Measurement Models

\begin{tabular}{|c|c|c|c|c|c|c|}
\hline \multirow{2}{*}{ Items } & \multicolumn{2}{|l|}{ Time 1} & \multicolumn{2}{|l|}{ Time 2} & \multicolumn{2}{|c|}{ Longitudinal (invariant) } \\
\hline & $\lambda$ & $\delta$ & $\lambda$ & $\delta$ & $\lambda$ & $\delta$ \\
\hline \multicolumn{7}{|c|}{ Intensity of positive affect } \\
\hline Item 1 & 830 & .311 & .829 & .313 & .836 & .302 \\
\hline Item 2 & .755 & .430 & .902 & .186 & .813 & .339 \\
\hline Item 3 & .777 & .396 & .826 & .318 & .790 & .376 \\
\hline Item 4 & 424 & .820 & 403 & .837 & 406 & .835 \\
\hline Item 5 & .773 & .403 & .796 & .367 & .765 & .414 \\
\hline Item 6 & .575 & .669 & 682 & .535 & 604 & .636 \\
\hline Item 7 & 486 & .764 & .511 & .739 & .516 & .733 \\
\hline Item 8 & .543 & .705 & 641 & .589 & .568 & .678 \\
\hline Item 9 & 645 & .583 & .714 & .490 & 651 & .576 \\
\hline Item 10 & 665 & .558 & .754 & .432 & 691 & .522 \\
\hline$\omega$ & .881 & & 912 & & .891 & \\
\hline \multicolumn{7}{|c|}{ Intensity of negative affect } \\
\hline Item 1 & 650 & .578 & .725 & .474 & 669 & .553 \\
\hline Item 2 & 689 & .525 & .567 & .679 & 651 & .576 \\
\hline Item 3 & .792 & .373 & .812 & .340 & .811 & .342 \\
\hline Item 4 & .785 & .384 & .749 & .439 & .774 & .401 \\
\hline Item 5 & 666 & .556 & .788 & .378 & .703 & .506 \\
\hline Item 6 & .789 & .378 & .799 & .362 & .799 & .362 \\
\hline Item 7 & .736 & .459 & .688 & .527 & .716 & .488 \\
\hline Item 8 & .773 & .402 & .817 & .332 & .774 & .401 \\
\hline Item 9 & 681 & .537 & .774 & .400 & .701 & .509 \\
\hline Item 10 & .832 & .307 & .871 & .242 & .846 & .284 \\
\hline$\omega$ & 924 & & 932 & & 926 & \\
\hline \multicolumn{7}{|c|}{ Direction of positive affect } \\
\hline Item 1 & .872 & .240 & .867 & .249 & .872 & .240 \\
\hline Item 2 & 914 & .164 & 932 & .131 & .927 & .141 \\
\hline Item 3 & .888 & .212 & .954 & .091 & .916 & .161 \\
\hline Item 4 & 217 & .953 & 157 & .975 & .205 & .958 \\
\hline Item 5 & .801 & .359 & .842 & .291 & .808 & .348 \\
\hline Item 6 & .710 & .496 & .788 & .378 & .733 & .463 \\
\hline Item 7 & .611 & .626 & .666 & .557 & .634 & .598 \\
\hline Item 8 & .723 & .477 & .771 & .405 & .731 & .466 \\
\hline Item 9 & .884 & .218 & 919 & .156 & .892 & .204 \\
\hline Item 10 & .892 & .205 & .853 & .272 & .869 & .245 \\
\hline$\omega$ & 935 & & 945 & & .938 & \\
\hline \multicolumn{7}{|c|}{ Direction of negative affect } \\
\hline Item 1 & .799 & .361 & .860 & .260 & .820 & .328 \\
\hline Item 2 & 887 & .213 & .891 & .206 & .886 & .214 \\
\hline Item 3 & 907 & .177 & .891 & .206 & 901 & .188 \\
\hline Item 4 & 890 & .207 & .880 & .226 & .887 & .214 \\
\hline Item 5 & 868 & .247 & .925 & .144 & .883 & .221 \\
\hline Item 6 & .879 & .227 & .942 & .113 & .900 & .191 \\
\hline Item 7 & .889 & .209 & .864 & .253 & .883 & .221 \\
\hline Item 8 & .882 & .222 & .841 & .294 & .875 & .234 \\
\hline Item 9 & 960 & .079 & .901 & .187 & .948 & .102 \\
\hline Item 10 & 960 & .078 & .958 & .081 & .966 & .067 \\
\hline$\omega$ & .975 & & .976 & & .976 & \\
\hline
\end{tabular}

Note. $\lambda$ : factor loading; $\delta$ : item uniqueness; $\omega$ : omega coefficient of model-based composite reliability. 
Table S4

Standardized Factor Loadings $(\lambda)$ and Uniquenesses $(\delta)$ for the Predictors/Outcomes Models

\begin{tabular}{|c|c|c|c|c|c|c|}
\hline \multirow{2}{*}{ Items } & \multirow{2}{*}{$\begin{array}{c}\text { Time } 1 \\
\lambda\end{array}$} & \multicolumn{3}{|c|}{ Time 2} & \multicolumn{2}{|c|}{ Longitudinal (invariant) } \\
\hline & & $\delta$ & $\lambda$ & $\delta$ & $\lambda$ & $\delta$ \\
\hline \multicolumn{7}{|l|}{$\overline{\text { Predictors }}$} \\
\hline \multicolumn{7}{|l|}{ Autonomy (S-factor) } \\
\hline Item 1 & .448 & .397 & .611 & .277 & .292 & .427 \\
\hline Item 2 & .369 & .481 & .182 & .489 & .212 & .513 \\
\hline Item 3 & .484 & .368 & .519 & .425 & .491 & .369 \\
\hline Item 4 & .402 & .518 & .469 & .475 & .494 & .456 \\
\hline Item 5 & .574 & .200 & .618 & .277 & .617 & .167 \\
\hline$\omega$ & .596 & & .748 & & .697 & \\
\hline \multicolumn{7}{|l|}{ Relatedness (S-factor) } \\
\hline Item 1 & .228 & .455 & .402 & .325 & .226 & .446 \\
\hline Item 2 & .557 & .264 & .610 & .227 & .440 & .349 \\
\hline Item 3 & .284 & .519 & .348 & .462 & .345 & .474 \\
\hline Item 4 & .445 & .619 & .326 & .719 & .381 & .661 \\
\hline Item 5 & .333 & .577 & .301 & .464 & .383 & .484 \\
\hline$\omega$ & .584 & & .642 & & .566 & \\
\hline \multicolumn{7}{|l|}{ Competence (S-factor) } \\
\hline Item 1 & .619 & .306 & .383 & .331 & .518 & .385 \\
\hline Item 2 & .413 & .298 & .633 & .063 & .536 & .216 \\
\hline Item 3 & .405 & .543 & .032 & .526 & .328 & .563 \\
\hline Item 4 & -.196 & .267 & -.125 & .347 & -.051 & .412 \\
\hline Item 5 & .531 & .328 & .544 & .232 & .558 & .290 \\
\hline$\omega$ & .729 & & .663 & & .680 & \\
\hline \multicolumn{7}{|l|}{ Need satisfaction (G-factor) } \\
\hline Item 1 Autonomy & .634 & & .591 & & .698 & \\
\hline Item 2 Autonomy & .619 & & 691 & & .665 & \\
\hline Item 3 Autonomy & .630 & & .554 & & .624 & \\
\hline Item 4 Autonomy & .566 & & .552 & & .548 & \\
\hline Item 5 Autonomy & .686 & & .584 & & .672 & \\
\hline Item 1 Relatedness & .557 & & .723 & & .589 & \\
\hline Item 2 Relatedness & .729 & & .732 & & .705 & \\
\hline Item 3 Relatedness & .542 & & .688 & & .574 & \\
\hline Item 4 Relatedness & .834 & & .798 & & .765 & \\
\hline Item 5 Relatedness & .625 & & .687 & & .631 & \\
\hline Item 1 Competence & .702 & & .717 & & .709 & \\
\hline Item 2 Competence & .653 & & .633 & & .676 & \\
\hline Item 3 Competence & .633 & & .646 & & .638 & \\
\hline Item 4 Competence & .428 & & .418 & & .441 & \\
\hline Item 5 Competence & .559 & & .668 & & .607 & \\
\hline$\omega$ & .935 & & .943 & & .936 & \\
\hline \multicolumn{7}{|l|}{ Autonomy support } \\
\hline Item 1 & .842 & .290 & .775 & .399 & .830 & .311 \\
\hline Item 2 & .805 & .352 & .803 & .355 & .801 & .359 \\
\hline Item 3 & .882 & .222 & .852 & .274 & .872 & .240 \\
\hline Item 4 & .830 & .312 & .859 & .262 & .845 & .286 \\
\hline Item 5 & .854 & .271 & .856 & .268 & .859 & .261 \\
\hline Item 6 & .902 & .187 & .912 & .168 & .904 & .183 \\
\hline Item 7 & .903 & .185 & .911 & .170 & .908 & .176 \\
\hline Item 8 & .920 & .154 & .945 & .107 & .922 & .151 \\
\hline Item 9 & .810 & .344 & .841 & .293 & .814 & .337 \\
\hline$\omega$ & .968 & & .960 & & .963 & \\
\hline
\end{tabular}


Positive and Negative Affect 37

\begin{tabular}{lcccccc}
\hline & Time 1 & \multicolumn{3}{c}{ Time 2} & \multicolumn{2}{c}{ Longitudinal (invariant) } \\
Items & $\lambda$ & $\delta$ & $\lambda$ & $\delta$ & $\lambda$ & $\delta$ \\
\hline Outcomes & & & & & & \\
Work-family conflict & & & & & & \\
$\quad$ Item 1 & .899 & .192 & .921 & .152 & .900 & .190 \\
$\quad$ Item 2 & .882 & .222 & .915 & .163 & .894 & .200 \\
$\quad$ Item 3 & .932 & .131 & .975 & .049 & .951 & .095 \\
$\quad .931$ & & .956 & & .940 & \\
Turnover & & & & & & \\
$\quad$ Item 1 & .661 & .563 & .734 & .461 & .683 & .534 \\
$\quad$ Item 2 & .963 & .072 & .988 & .024 & .954 & .090 \\
$\quad$ Item 3 & .923 & .148 & .884 & .218 & .928 & .139 \\
$\quad \omega$ & .892 & & .906 & & .896 & \\
\hline Note. $\lambda:$ factor loading; $\delta$ : item uniqueness; $\omega:$ omega coefficient of model-based composite reliability
\end{tabular}

Note. $\lambda$ : factor loading; $\delta$ : item uniqueness; $\omega$ : omega coefficient of model-based composite reliability. 


\section{Table S5}

Correlations between Variables Used in the Present Study

\begin{tabular}{|c|c|c|c|c|c|c|c|c|c|c|c|}
\hline Variable & 1 & 2 & 3 & 4 & 5 & 6 & 7 & 8 & 9 & 10 & 11 \\
\hline 1. Sex & - & & & & & & & & & & \\
\hline 2. Age & .080 & - & & & & & & & & & \\
\hline 3. Education level & $.260 * *$ & $-.499 * *$ & - & & & & & & & & \\
\hline 4. Positive affect intensity $\mathrm{T} 1^{1}$ & $-.296 * *$ & -.038 & -.113 & - & & & & & & & \\
\hline 5. Negative affect intensity $\mathrm{T} 1^{1}$ & .091 & -.071 & .068 & $-.458 * *$ & - & & & & & & \\
\hline 6. Positive affect direction $\mathrm{T} 1^{1}$ & -.042 & -.101 & .066 & $.729 * *$ & $-.388 * *$ & - & & & & & \\
\hline 7. Negative affect direction $\mathrm{T} 1^{1}$ & .021 & -.041 & -.117 & -.125 & $.203 *$ & $-.328 * *$ & - & & & & \\
\hline 8. Need satisfaction (G-factor) $\mathrm{T} 1^{1}$ & $-.183 *$ & -.042 & -.100 & $.657 * *$ & $-.442 * *$ & $.514 * *$ & -.017 & - & & & \\
\hline 9. Autonomy support $\mathrm{T} 1^{1}$ & -.016 & -.114 & .092 & $.398 * *$ & $-.330 * *$ & $.398 * *$ & -.038 & $.757 * *$ & - & & \\
\hline 10. Work-family conflict $\mathrm{T} 1^{1}$ & -.170 & $-192 *$ & .134 & -.106 & .141 & -.087 & .053 & $-.227^{*}$ & -.057 & - & \\
\hline 11. Turnover intentions $\mathrm{T} 1^{1}$ & -.084 & .078 & -.065 & $-.429 * *$ & $.413 * *$ & $-.347 * *$ & -.023 & $-.659 * *$ & $-.598 * *$ & $.321 * *$ & - \\
\hline 12. Absenteeism T1 & -.040 & .075 & $-.187^{*}$ & .016 & $.183^{*}$ & -.015 & .071 & .038 & -.001 & -.055 & $.196 *$ \\
\hline 13. Positive affect intensity $\mathrm{T} 2^{1}$ & $-276 * *$ & -.023 & -.104 & $.861 * *$ & $-.401 * *$ & $.672 * *$ & $-.181 *$ & $.560 * *$ & $.354 * *$ & -.068 & $-.327 * *$ \\
\hline 14. Negative affect intensity $\mathrm{T} 2^{1}$ & .116 & -.077 & .036 & $-.382 * *$ & $.806 * *$ & $-.344 * *$ & $.233 * *$ & $-.383 * *$ & $-.257 * *$ & .144 & $.320 * *$ \\
\hline 15. Positive affect direction $\mathrm{T} 2^{1}$ & .008 & -.143 & .101 & $.500 * *$ & -.161 & $.668 * *$ & $-.258 * *$ & $.360 * *$ & $.291 * *$ & -.028 & $-.235 * *$ \\
\hline 16. Negative affect direction $\mathrm{T} 2^{1}$ & -.051 & .055 & -.151 & -.108 & -.030 & $-.201 *$ & $.393 * *$ & -.090 & -.056 & .108 & .091 \\
\hline 17. Need satisfaction (G-factor) $\mathrm{T} 2^{1}$ & -.176 & -.126 & -.062 & $.535 * *$ & $-.308 * *$ & $.386 * *$ & -.044 & $.680 * *$ & $.486 * *$ & -.067 & $-.432 * *$ \\
\hline 18. Autonomy support $\mathrm{T} 2^{1}$ & -.010 & -.163 & .046 & $.197 *$ & -.089 & .143 & .032 & $.527 * *$ & $.651 * *$ & .124 & $-.307 * *$ \\
\hline 19. Work-family conflict $\mathrm{T} 2^{1}$ & -.073 & -.067 & .063 & -.128 & .065 & -.123 & -.058 & $-.253 * *$ & -.045 & $.632 * *$ & $.248 * *$ \\
\hline 20. Turnover intentions $\mathrm{T} 2^{1}$ & .022 & .031 & .052 & $-.380 * *$ & $.354 * *$ & $-.237 * *$ & .007 & $-.476 * *$ & $-.361 * *$ & $.243 * *$ & $.670 * *$ \\
\hline 21. Absenteeism T2 & .043 & -.052 & -.009 & .078 & .149 & .090 & .042 & -.028 & -.107 & .028 & $.206 *$ \\
\hline
\end{tabular}




\section{Table S5 (Continued)}

Correlations between Variables Used in the Present Study

\begin{tabular}{|c|c|c|c|c|c|c|c|c|c|c|}
\hline Variable & 12 & 13 & 14 & 15 & 16 & 17 & 18 & 19 & 20 & 21 \\
\hline 12. Absenteeism T1 & - & & & & & & & & & \\
\hline 13. Positive affect intensity $\mathrm{T} 2^{1}$ & .081 & - & & & & & & & & \\
\hline 14. Negative affect intensity $\mathrm{T} 2^{1}$ & .138 & $-.405 * *$ & - & & & & & & & \\
\hline 15. Positive affect direction $\mathrm{T} 2^{1}$ & .127 & $.671 * *$ & $-.303 * *$ & - & & & & & & \\
\hline 16. Negative affect direction $\mathrm{T} 2^{1}$ & .000 & -.080 & $.199 *$ & $-.352 * *$ & - & & & & & \\
\hline 17. Need satisfaction (G-factor) $\mathrm{T} 2^{1}$ & .110 & $.610 * *$ & $-.323 * *$ & $.420 * *$ & -.133 & - & & & & \\
\hline 18. Autonomy support $\mathrm{T} 2^{1}$ & .118 & $.265 * *$ & -.087 & $.213^{*}$ & -.041 & $.738 * *$ & - & & & \\
\hline 19. Work-family conflict $\mathrm{T} 2^{1}$ & -.104 & -.083 & .171 & -.057 & .169 & $-.200 *$ & .070 & - & & \\
\hline 20. Turnover intentions $\mathrm{T} 2^{1}$ & .111 & $-.380 * *$ & $.347 * *$ & $-.244 * *$ & $.209 *$ & $-.556 * *$ & $-.305 * *$ & $.412 * *$ & - & \\
\hline 21. Absenteeism T2 & $.598 * *$ & .127 & .148 & $.271 * *$ & -.124 & .000 & -.060 & .034 & .112 & - \\
\hline
\end{tabular}

Note. $* p<.05 ; * * p<.01 ;{ }^{1}$ : These variables are estimated from factor scores with a standard deviation of 1 and a mean of 0. 


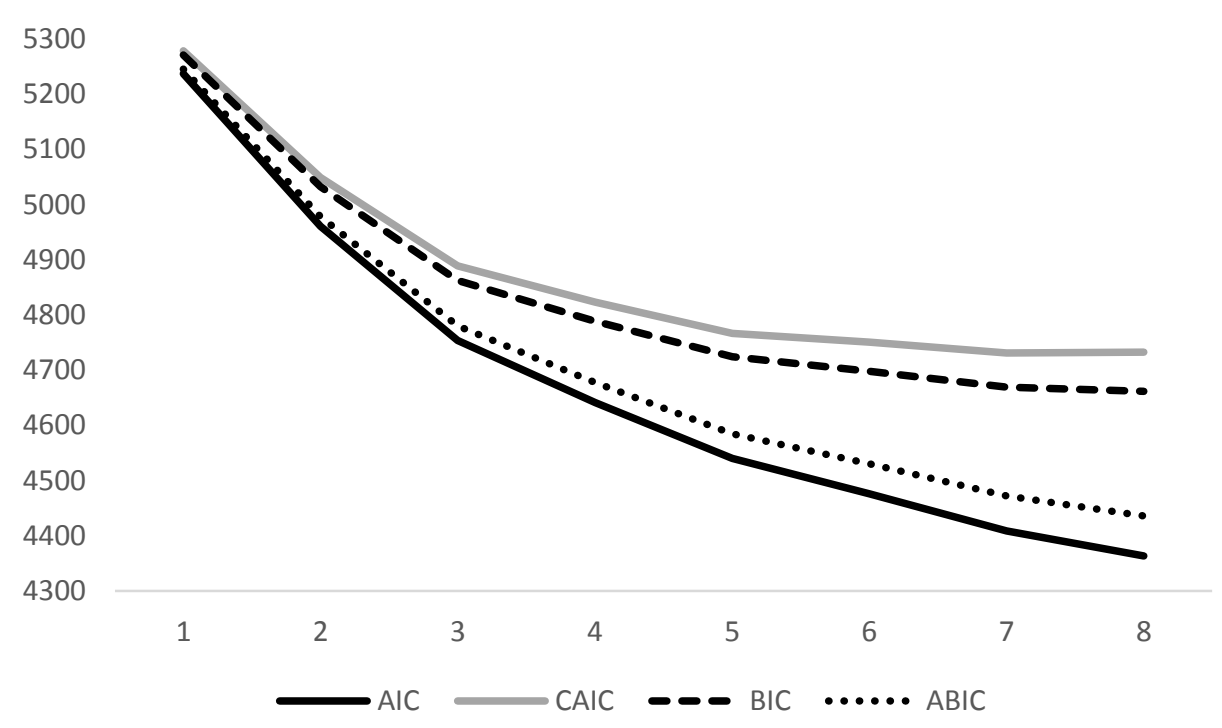

Figure S1

Elbow Plot of the Information Criteria for the Latent Profile Analyses (Time 1)

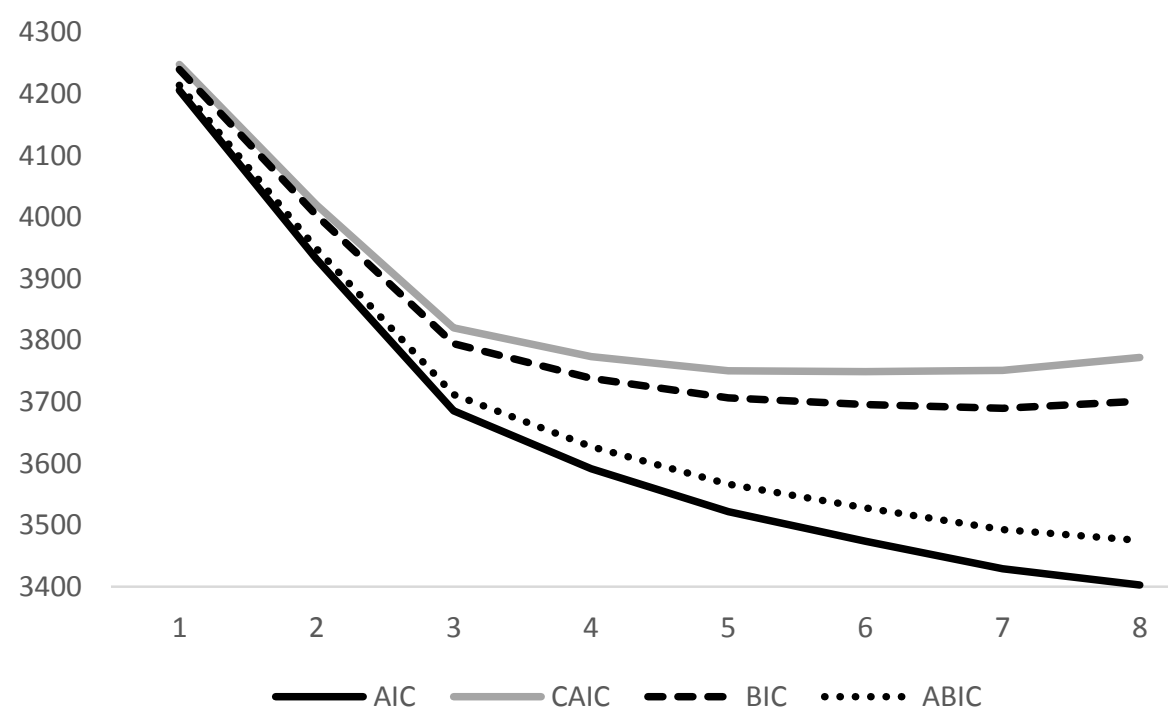

Figure S2

Elbow Plot of the Information Criteria for the Latent Profile Analyses (Time 2) 


\section{Table S6}

Final Longitudinal Latent Profiles (Partial Dispersion Similarity): Detailed Estimates

\begin{tabular}{|c|c|c|c|c|c|c|c|}
\hline & $\begin{array}{l}\text { Profile } 1 \\
\text { Mean }[\mathrm{CI}]\end{array}$ & $\begin{array}{l}\text { Prof } \\
\text { Mean }\end{array}$ & & & $\begin{array}{l}\text { ofile } 3 \\
\operatorname{an}[\mathrm{CI}]\end{array}$ & $\begin{array}{c}\text { Profile } 4 \\
\text { Mean }[\mathrm{CI}]\end{array}$ & $\begin{array}{l}\text { Profile 5 } \\
\text { Mean [CI] }\end{array}$ \\
\hline $\begin{array}{l}\text { Intensity of } \\
\text { positive affect }\end{array}$ & $\begin{array}{c}.458[.150 ; \\
.766]\end{array}$ & $\begin{array}{r}-.558[. \\
.19\end{array}$ & $25 ;-$ & & $\begin{array}{l}8[.697 ; \\
999]\end{array}$ & $\begin{array}{c}-1.101[-1.348 \\
-.854]\end{array}$ & $\begin{array}{c}-.017[-.148 ; \\
.114]\end{array}$ \\
\hline $\begin{array}{l}\text { Intensity of } \\
\text { negative affect }\end{array}$ & $\begin{array}{c}-.876[-1.152 ; \\
.600]\end{array}$ & $\begin{array}{r}.101[- \\
.39\end{array}$ & 97 & -.44 & $\begin{array}{l}{[-.592 ;-} \\
306]\end{array}$ & $\begin{array}{c}.800[.514 ; \\
1.086]\end{array}$ & $\begin{array}{c}.031[-.067 ; \\
.129]\end{array}$ \\
\hline $\begin{array}{l}\text { Direction of } \\
\text { positive affect }\end{array}$ & $\begin{array}{c}.173[-.146 ; \\
.492]\end{array}$ & $\begin{array}{r}-1.448[- \\
-1.42\end{array}$ & $\begin{array}{l}.472 ; \\
]\end{array}$ & & $\begin{array}{l}3[.786 ; \\
.060]\end{array}$ & $\begin{array}{c}-.850[-1.093 ;- \\
.607]\end{array}$ & $\begin{array}{c}-.065[-.175 ; \\
.045]\end{array}$ \\
\hline $\begin{array}{l}\text { Direction of } \\
\text { negative affect }\end{array}$ & $\begin{array}{c}.896[.886 ; \\
.906]\end{array}$ & $\begin{array}{r}.924[. \\
.93\end{array}$ & & -.37 & $\begin{array}{l}{[-.542 ;-} \\
204]\end{array}$ & $\begin{array}{c}.051[-.108 ; \\
.210]\end{array}$ & $\begin{array}{c}.027[-.038 \\
.092]\end{array}$ \\
\hline & Profile 1 & Profile 2 & Profi & & Profile 4 & $\begin{array}{c}\text { Profile } 5 \\
\text { Time } 1\end{array}$ & $\begin{array}{l}\text { Profile } 5 \\
\text { Time } 2\end{array}$ \\
\hline & $\begin{array}{c}\text { Variance } \\
{[\mathrm{CI}]}\end{array}$ & $\begin{array}{l}\text { Variance } \\
{[\mathrm{CI}]}\end{array}$ & Var & & Variance [C & $\begin{array}{l}\text { Variance } \\
{[\mathrm{CI}]}\end{array}$ & $\begin{array}{l}\text { Variance } \\
{[\mathrm{CI}]}\end{array}$ \\
\hline $\begin{array}{l}\text { Intens } \\
\text { positi }\end{array}$ & $\begin{array}{c}.955[.404 ; \\
1.506]\end{array}$ & $\begin{array}{c}.845[.478 ; \\
1.212]\end{array}$ & $\begin{array}{r}.318 \\
.4\end{array}$ & & $\begin{array}{c}.417[.219 \\
.615]\end{array}$ & $\begin{array}{c}.255[.171 ; \\
.339]\end{array}$ & $\begin{array}{c}.187[.148 ; \\
.226]\end{array}$ \\
\hline $\begin{array}{l}\text { Intensity of } \\
\text { negative affect }\end{array}$ & $\begin{array}{c}.291[.124 ; \\
.458]\end{array}$ & $\begin{array}{c}.606[.365 ; \\
.847]\end{array}$ & $\begin{array}{r}.445 \\
.5\end{array}$ & & $\begin{array}{c}.527[.260 \\
.794]\end{array}$ & $\begin{array}{c}.631[.513 ; \\
.749]\end{array}$ & $\begin{array}{c}.349[.296 ; \\
.402]\end{array}$ \\
\hline $\begin{array}{l}\text { Direction of } \\
\text { positive affect }\end{array}$ & $\begin{array}{c}.823[.404 ; \\
1.242]\end{array}$ & $\begin{array}{c}.003[.001 ; \\
.005]\end{array}$ & $\begin{array}{r}.233[ \\
.28\end{array}$ & & $\begin{array}{c}.620[.346 \\
.894]\end{array}$ & $\begin{array}{c}.176[.072 ; \\
.280]\end{array}$ & $\begin{array}{c}.143[.110 ; \\
.176]\end{array}$ \\
\hline $\begin{array}{l}\text { Direction of } \\
\text { negative affect }\end{array}$ & $\begin{array}{c}.000[.000 ; \\
.000]\end{array}$ & $\begin{array}{c}.001[.001 ; \\
.001]\end{array}$ & $\begin{array}{r}.788 \\
1.1\end{array}$ & $\begin{array}{l}\text { 423; } \\
3]\end{array}$ & $\begin{array}{c}.538[.315 \\
.761]\end{array}$ & $\begin{array}{c}.824[.652 ; \\
.996]\end{array}$ & $\begin{array}{c}.129[.100 ; \\
.158]\end{array}$ \\
\hline
\end{tabular}

Note. $\mathrm{CI}=95 \%$ confidence interval; the profile indicators are estimated from factor scores with a standard deviation of 1 and a mean of 0; Profile 1: Low Negative Affect Facilitators; Profile 2: Moderately Low Positive Affect Incapacitators; Profile 3: High Positive Affect Facilitators; Profile 4: Very Low Positive Affect Incapacitators; Profile 5: Normative. 